\title{
Unemployment Insurance in a Sticky-Price Model with Worker Moral Hazard
}

\author{
Gregory E. Givens* \\ Assistant Professor of Economics \\ Department of Economics and Finance \\ Jennings A. Jones College of Business \\ Middle Tennessee State University \\ Murfreesboro, TN 37132 \\ ggivens@mtsu . edu
}

First Draft: July 2008

\begin{abstract}
This paper studies the role of unemployment insurance in a sticky-price model that features an efficiency-wage view of the labor market based on unobservable effort. The risk-sharing mechanism central to the model permits, but does not force, agents to be fully insured. Structural parameters are estimated using a maximum-likelihood procedure on US data. Formal hypothesis tests reveal that the data favor a model in which agents only partially insure each other against employment risk. The results also show that limited risk sharing helps the model capture many salient properties of the business cycle that a restricted version with full insurance fails to explain.
\end{abstract}

Keywords: Unemployment, Partial Insurance, Efficiency Wages, Sticky Prices JEL Classification: E31, E32, E52

\footnotetext{
*Financial assistance for this project was provided by the MTSU Office of Research and Sponsored Programs. I assume full responsibility for all errors and omissions.
} 


\section{Introduction}

Unemployment is a ubiquitous feature of modern economies. Yet in a dynamic general equilibrium setting, unemployment does not emerge unless certain frictions, such as efficiency wages (e.g., Danthine and Donaldson, 1990; Gomme, 1999) or search externalities (e.g., Merz, 1995; Andolfatto, 1996), are built into the labor market. A frequent assumption underlying these models is that workers perfectly insure each other against variations in labor income resulting from job loss. The rationale is that insurance contracts make the intertemporal decisions independent of one's employment status, thereby circumventing complications that arise from heterogeneous work histories. Restoring homogeneity to the model, the argument goes, allows the researcher to focus more on the role of labor market imperfections in accounting for unemployment and other important aspects of the data.

Notwithstanding the desire to highlight the labor market, the assumption of complete risk sharing has two potential drawbacks that have received little attention in the macroeconomic literature. First, there is no compelling evidence that points to full insurance as an empirically realistic premise. To the contrary, numerous studies show that temporary unemployment spells cause a nontrivial decline in personal consumption spending (e.g., Dynarski and Sheffrin, 1987; Gruber, 1997). At the very least, it would be useful to have a business cycle model that is more consistent with our understanding of the risk-sharing behavior of consumers. Second, the assumption of full insurance is appropriate provided its effect on the main conclusions of the model are negligible. It is difficult to assess whether full insurance meets this standard without also comparing the model to one that embodies alternative insurance possibilities.

In light of these issues, this paper estimates an equilibrium model of unemployment that incorporates a menu of different risk-sharing options, and by doing so, departs from the widespread practice of considering only the case of full insurance. More specifically, this 
paper asks whether the assumption of full insurance is sufficient to explain most of the key properties of the US business cycle, or whether limiting the insurance opportunities substantially improves the fit of the model. To that end, I construct a dynamic sticky-price model that gives prominence to a frictional labor market along the lines of Alexopoulos (2004). The central idea is that workers face a temptation to shirk that arises from firms' inability to monitor effort. Consequently, employers design a payment mechanism that discourages shirking. The outcome corresponds to an efficiency wage that exceeds the market-clearing level and makes unemployment an equilibrium feature of the economy.

Unemployment insurance enters the model by means of an income-pooling device that permits, but does not force, agents to fully insure each other against employment risk. Workers contribute a portion of their earnings into a fund that is redistributed equally to the unemployed. Individual contributions are governed by an exogenous function that defines the scope of insurance coverage. The specification used in the model can accommodate any one of a continuum of different arrangements, including both partial and full insurance cases. ${ }^{1}$

The paper proceeds by estimating the parameters of the model using a maximumlikelihood procedure with quarterly US data on per capita consumption, investment, the real wage, inflation, and the nominal interest rate. Two versions of the model are estimated that differ in their treatment of risk sharing. One leaves the insurance parameter unconstrained, allowing the data to ascertain the extent of risk sharing among agents. The second restricts this parameter prior to estimation to guarantee full insurance in equilibrium. Likelihood ratio tests provide the basis for a formal comparison between the restricted, full insurance version and the unrestricted alternative that allows for partial insurance.

Econometric results indicate that the data prefer a model in which agents are only partially insured. Point estimates of the insurance parameter imply that consumption of unem-

\footnotetext{
${ }^{1}$ I avoid the computational problems related to consumption heterogeneity by assuming a family construct that makes all decisions regarding the accumulation of assets over time (e.g., Alexopoulos, 2004; Danthine and Kurmann, 2004).
} 
ployed members is about 40 percent less than that of employed members. Likelihood ratio tests of the null hypothesis of full insurance are easily rejected at standard significance levels.

Results from a broad comparison of second moments provide additional, albeit less formal, evidence in favor of limited risk sharing. For example, the partial insurance model succeeds in matching the low relative volatility of the real wage and the small correlation between wages and output found in the data. Partial insurance also helps capture the observed degree of wage persistence, as reflected in the correlations between current and lagged real wages. Finally, variance decompositions show that the unrestricted model is more consistent with the belief that monetary shocks have a modest impact on the business cycle, while investment-specific technology shocks play a dominant role in driving economic fluctuations. These findings, when viewed together, demonstrate the clear improvement in model fit that can be obtained by abandoning the strict assumption of perfect risk sharing.

\subsection{Related Literature}

There are a few recent papers showing that the performance of business cycle models can be improved in certain areas by restricting the insurance opportunities available to agents. Using a GMM procedure, Alexopoulos (2004) estimates a flexible-price model with unobservable effort driven by technology and fiscal shocks. Two distinct insurance arrangements are examined by imposing alternative calibrations on the wage-pooling equation. The first is the case of full insurance, and the second is a partial insurance plan whereby consumption declines by about 22 percent when unemployed. The results indicate that partial insurance helps amplify and propagate the responses to both shocks while improving the volatility and co-movement of real wages and employment. In a related paper, Alexopoulos (2007) shows that partial insurance also generates a more sluggish price response to monetary shocks from the perspective of a limited participation model.

Aside from the inclusion of sticky prices, this paper extends Alexopoulos' research by 
conducting statistical inference on the insurance component of the model. Alexopoulos bases her comparison of insurance schemes on an assortment of key second moments, leaving open the question of whether partial insurance actually improves the empirical fit of the model. I impose greater econometric discipline in this paper by estimating the degree of risk sharing in an environment that nests full insurance as a special case. The maximumlikelihood strategy employed here enables the researcher to formally test the null hypothesis of complete risk sharing against the alternative of partial insurance.

Givens (2008) develops a monetary business cycle model that combines sticky prices with imperfectly observable labor effort. Similar to the present study, his model also features an insurance mechanism that allows for varying degrees of risk sharing. Through dynamic simulations, Givens finds that limiting the scope of insurance coverage leads to greater persistence in the path of output following a monetary shock as well as more sluggishness in the response profile of inflation.

By estimating the model via maximum likelihood, this paper departs from Givens' study, the results of which are predicated on a less rigorous calibration of the parameters. In the process of taking the model to the data, a number of extra structural features are added. These include endogenous capital accumulation with adjustment costs, habit formation in consumption, dynamic price indexation, and an interest rate rule governing the conduct of monetary policy. The model is also augmented by a richer set of structural disturbances, namely, neutral and investment-specific technology shocks, a preference shock, a price markup shock, a monetary shock, and a labor supply shock affecting the hours margin.

\section{The Economic Model}

The model blends sticky product prices with an efficiency-wage theory of the labor market based on unobservable effort. It is populated by five types of agents: a representative family, 
a continuum of family members, a competitive finished goods-producing firm, a continuum of intermediate goods-producing firms, and a government.

\subsection{Families}

The representative family has a continuum of members of measure one. Randomly selected $N_{t}$ members receive job offers every period, while the remaining $1-N_{t}$ are unemployed. Because unemployment generates income dispersion, I follow Alexopoulos (2004) in assuming that the family accumulates assets over time. Denying individuals access to financial markets conserves the representative agent framework in an economy with positive unemployment.

The family brings $K_{t}$ units of capital and $R_{t-1} B_{t-1}$ units of nominal bond wealth into period $t$, where $R_{t}$ is the gross nominal interest rate between $t$ and $t+1$ on bond purchases $B_{t}$. It then leases its capital stock to a $[0,1]$ continuum of intermediate good firms at a competitive rental rate $r_{t}^{k}$. At the end of the period, it receives a flow of real dividend payments $\int_{0}^{1} D_{t}(i) d i$ from ownership of those firms. Together with bond and dividend earnings, returns from capital are used to purchase a portfolio of new bonds $B_{t}$, investment goods $I_{t}$, and a stream of consumption benefits $C_{t}^{f}$ for the members. The family distributes consumption equally before jobs commence, making $C_{t}^{f}$ a lower bound on the amount of consumption available to members who face employment risk. The budget constraint is then given by

$$
C_{t}^{f}+I_{t}+\frac{B_{t}}{P_{t}} \leq r_{t}^{k} K_{t}+\frac{R_{t-1} B_{t-1}}{P_{t}}+\int_{0}^{1} D_{t}(i) d i
$$

where $P_{t}$ denotes the price of the finished good that can be either consumed or invested.

The law of motion for the family's capital stock is given by

$$
K_{t+1}=(1-\delta) K_{t}-\frac{\phi}{2}\left(\frac{I_{t}}{K_{t}}-\delta\right)^{2} K_{t}+a_{t} I_{t}
$$


where the depreciation rate $\delta \in(0,1)$ and $\frac{\phi}{2}(\cdot)^{2}$ is an adjustment cost function with $\phi \geq 0$. In the spirit of Greenwood, Hercowitz, and Huffman (1988), the stochastic variable $a_{t}$ is an investment-specific technology shock that follows the autoregressive process

$$
\log a_{t}=\rho_{a} \log a_{t-1}+\varepsilon_{a, t}
$$

where $0<\rho_{a}<1$ and $\varepsilon_{a, t} \sim N\left(0, \sigma_{a}^{2}\right)$.

\subsubsection{Family Members}

Although members do not participate in asset markets, they can purchase additional consumption above the family minimum using wage income. Intermediate good firms offer one-period job contracts that request an effort level $e_{t}$ and work hours $h_{t}$ in exchange for an hourly real wage $w_{t}{ }^{2}$ The inability to perfectly monitor effort, however, invites employed members to shirk. Following Alexopoulos (2004), workers receive a fraction $s$ of their total wages upon entry, while the final payment of $(1-s) h_{t} w_{t}$ is awarded at the end of the period if shirking goes undetected. Shirking is detected with exogenous probability $d$. I model the shift length $h_{t}$ as an exogenous stochastic process: $h_{t}=h \varepsilon_{h, t}$, where $h$ is the average length of work hours and $\log \left(\varepsilon_{h, t}\right) \sim N\left(0, \sigma_{h}^{2}\right)$. Adding shocks to hours worked permits total hours $N_{t} h_{t}$ to vary along the intensive margin through exogenous changes in $h_{t}$ and along the extensive margin through endogenous fluctuations in $N_{t}{ }^{3}$

The government coordinates a fully funded insurance program to spread the income risk associated with unemployment. All employees pay an insurance fee $F_{t}$ that is pooled into

\footnotetext{
${ }^{2}$ I drop firm-specific notation when discussing the characteristics of employment contracts. Because they share a common production technology, contracts will not vary across firms.

${ }^{3} \mathrm{~A}$ more appealing model would feature endogenous variation in both employment and hours worked. Given the numerous studies showing that most of the cyclical variation in US total hours occurs along the extensive margin (e.g., King and Rebelo, 2000), forcing intensive margin adjustments to be purely exogenous may not be a particularly damaging assumption.
} 
one large fund totaling $N_{t} F_{t}$ and distributed equally to unemployed members. ${ }^{4}$ It follows that consumption will depend on one's employment status as well as the outcome of the firm's monitoring efforts. If an individual finds employment and is not detected shirking, his date- $t$ consumption will be

$$
C_{t}^{e}=C_{t}^{f}+h_{t} w_{t}-F_{t}
$$

If caught shirking, his consumption will be

$$
C_{t}^{s}=C_{t}^{f}+s h_{t} w_{t}-F_{t}
$$

after forfeiting the end-of-period bonus. If unemployed, his date- $t$ consumption will be the sum of family-purchased consumption and an equal share of the insurance fund given by

$$
C_{t}^{u}=C_{t}^{f}+\frac{N_{t} F_{t}}{1-N_{t}}
$$

The insurance fee is characterized by an exogenous formula that encompasses a menu of different risk sharing possibilities. Specifically,

$$
F_{t}=\sigma\left(1-N_{t}\right) h_{t} w_{t}
$$

where $\sigma \in[0,1]$ quantifies the scope of the insurance program. The government can fully insure workers by setting $\sigma=1$ since $C_{t}^{e}=C_{t}^{u}$ in this case. A partial insurance arrangement can be obtained by setting $0<\sigma<1$, guaranteeing that $C_{t}^{f}<C_{t}^{u}<C_{t}^{e}$ in equilibrium.

The utility function of a family member who consumes $C_{t}^{i}$ units of the finished good is

$$
U\left(C_{t}^{i}-b C_{t-1}, e_{t}\right)=\log \left(C_{t}^{i}-b C_{t-1}\right)+\theta \log \left(T-\vartheta_{t}\left[h_{t} e_{t}+\xi\right]\right),
$$

\footnotetext{
${ }^{4}$ Equilibrium outcomes would not change if the family, instead of the government, was responsible for administering unemployment benefits.
} 
where $\theta \geq 0, T$ is the time endowment, and $\vartheta_{t}$ is an indicator function equal to one if employed and providing effort. The parameter $\xi$ measures fixed costs of exerting nonzero effort. As in Smets and Wouters (2003), consumption $C_{t}^{i}$ appears relative to an external habit variable $b C_{t-1}$. The parameter $b \in[0,1]$ determines the degree of habit formation, where the reference variable corresponds to last period's average level of consumption $C_{t-1} .^{5}$

Because effort is imperfectly observable, workers encounter a moral hazard problem after accepting job offers. Specifically, they must decide whether supplying the mandatory effort is optimal given knowledge of the firm's exogenous monitoring technology. ${ }^{6}$ Alexopoulos (2006) demonstrates that employees will abide by the terms of the contract only if the resultant utility exceeds the expected utility from shirking. Workers will otherwise choose to elicit zero effort because any positive effort reduces utility and the wage forfeiture facing a detected shirker does not depend on the size of one's effort deficit. This means that workers will satisfy the conditions of employment provided they are incentive compatible, that is, if

$$
U\left(C_{t}^{e}-b C_{t-1}, e_{t}\right) \geq d U\left(C_{t}^{s}-b C_{t-1}, 0\right)+(1-d) U\left(C_{t}^{e}-b C_{t-1}, 0\right)
$$

\subsubsection{The Representative Family's Problem}

The family's objective is to maximize the present value of the average utility of its members. I show that employment contracts are incentive compatible in the next section, so workers will never shirk in equilibrium. Accordingly, family preferences take the form

$$
E_{0} \sum_{t=0}^{\infty} \beta^{t} g_{t}\left[N_{t} U\left(C_{t}^{e}-b C_{t-1}, e_{t}\right)+\left(1-N_{t}\right) U\left(C_{t}^{u}-b C_{t-1}, 0\right)\right]
$$

\footnotetext{
${ }^{5}$ Date- $t$ average consumption in the family is given by $C_{t}=\left(N_{t}-d N_{t}^{s}\right) C_{t}^{e}+d N_{t}^{s} C_{t}^{s}+\left(1-N_{t}\right) C_{t}^{u}$, where $N_{t}^{s}$ denotes the fraction of members who shirk.

${ }^{6} \mathrm{I}$ assume that family members who reject offers are ineligible to receive government unemployment benefits. This ensures that all offers are accepted and that unemployment will be strictly involuntary.
} 
where $\beta \in(0,1)$ is the discount factor. Sequences $\left\{C_{t}^{f}, B_{t}, I_{t}, K_{t+1}\right\}_{t=0}^{\infty}$ are chosen to maximize (9) subject to (1), (2), (3), and (5). The family treats $N_{t}$ parametrically during optimization because it does not believe that its actions affect employment outcomes. ${ }^{7}$ Finally, the stochastic variable $g_{t}$ is a shock affecting the time rate of preference and is governed by

$$
\log g_{t}=\rho_{g} \log g_{t-1}+\varepsilon_{g, t},
$$

where $0<\rho_{g}<1$ and $\varepsilon_{g, t} \sim N\left(0, \sigma_{g}^{2}\right)$. The preference shock appears in the Euler equation for $C_{t}^{f}$ linking current and expected future average marginal utility of consumption to the real interest rate. McCallum and Nelson (1999) argue that shocks like this one are similar to shocks originating in the goods market in traditional Keynesian IS-LM models.

\section{$2.2 \quad$ Firms}

Firms are of two types. The first type produces identical finished goods sold to families in competitive markets. The second type hires family members to produce intermediate goods that are sold to finished goods-producing firms in monopolistically competitive markets.

\subsubsection{Finished Good Firms}

A perfectly competitive firm manufactures finished goods $Y_{t}$ by assembling a $[0,1]$ continuum of intermediate goods indexed by $i$ using a Dixit and Stiglitz (1977) technology

$$
Y_{t}=\left[\int_{0}^{1} Y_{t}(i)^{\frac{1}{1+\eta_{t}}} d i\right]^{1+\eta_{t}},
$$

\footnotetext{
${ }^{7}$ Divorcing individuals from savings decisions also raises an issue about the treatment of habit formation. From the members' perspective, past average consumption is viewed as an external reference variable. With the family managing assets, however, the impact of marginal changes to $C_{t}^{f}$ on average consumption are internalized in the decision period.
} 
where $Y_{t}(i)$ measures the quantity of good $i$. Following Steinsson (2003), $\eta_{t}$ reflects the timevarying demand elasticity for intermediate goods that follows the exogenous process: $\eta_{t}=$ $\eta \varepsilon_{\eta, t}$. The parameter $\eta>0$ determines the steady-state markup and $\log \left(\varepsilon_{\eta, t}\right) \sim N\left(0, \sigma_{\eta}^{2}\right)$. Temporal variation in the elasticity of demand resembles, in equilibrium, a "cost-push" shock of the kind emphasized by Clarida, Galí, and Gertler (1999) and Ireland (2004b).

The finished good firm minimizes its unit cost of production every period by choosing

$$
Y_{t}(i)=\left[\frac{P_{t}(i)}{P_{t}}\right]^{-\frac{1+\eta_{t}}{\eta_{t}}} Y_{t}
$$

for all $i \in[0,1] . P_{t}(i)$ denotes the date- $t$ price of $Y_{t}(i)$. The marginal cost of producing a unit of the finished good is $P_{t}=\left[\int_{0}^{1} P_{t}(i)^{-\frac{1}{\eta_{t}}} d i\right]^{-\eta_{t}}$.

\subsubsection{Intermediate Good Firms}

The production technology for intermediate goods takes the form

$$
Y_{t}(i)=z_{t} k_{t}(i)^{\alpha}\left(\left[n_{t}(i)-n_{t}^{s}(i)\right] e_{t}(i) h_{t}\right)^{1-\alpha},
$$

where the capital share parameter $\alpha \in(0,1)$. The stochastic variable $z_{t}$ is a neutral technology shock that follows

$$
\log z_{t}=\left(1-\rho_{z}\right) \log z+\rho_{z} \log z_{t-1}+\varepsilon_{z, t}
$$

where $0<\rho_{z}<1, z>0$, and $\varepsilon_{z, t} \sim N\left(0, \sigma_{z}^{2}\right)$. Inputs $k_{t}(i), n_{t}(i), n_{t}^{s}(i)$, and $e_{t}(i)$ represent the date- $t$ capital services, number of family members, number of shirkers, and effort levels employed by firm $i$, respectively. Given the timing of wage payments and the fact that shirkers produce no output, it is never profitable to hire workers who are inclined to shirk. As a result, firms design labor contracts that elicit effort from all employees. 
During period $t$, firms select $\left\{k_{t}(i), n_{t}(i), w_{t}(i), e_{t}(i)\right\}$ to minimize unit production costs $k_{t}(i) r_{t}^{k}+n_{t}(i) h_{t} w_{t}(i)$ subject to $z_{t} k_{t}(i)^{\alpha}\left(n_{t}(i) e_{t}(i) h_{t}\right)^{1-\alpha} \geq 1$ and the incentive compatibility constraint (8). The latter constraint holds with equality because firms want to compensate employees no more than what is minimally needed to induce effort. By substituting (3), (5), and (7) into (8), effort can be expressed as a function of the real wage,

$$
e_{t}(i)=e\left(w_{t}(i)\right)=\frac{T-\xi}{h_{t}}-\frac{T}{h_{t}}\left(\frac{C_{t}^{f}+h_{t} w_{t}(i)-F_{t}-b C_{t-1}}{C_{t}^{f}+s h_{t} w_{t}(i)-F_{t}-b C_{t-1}}\right)^{-d / \theta}
$$

Subject to (11), cost minimization yields the familiar Solow (1979) condition

$$
\frac{w_{t}(i) e^{\prime}\left(w_{t}(i)\right)}{e\left(w_{t}(i)\right)}=1
$$

which implies that firms select the real wage to minimize costs per unit of effort. ${ }^{8}$ The efficiency wage satisfying (12) will generally exceed the wage that would prevail in a Walrasian labor market with perfect monitoring. The result is positive unemployment in equilibrium.

After differentiating (11) with respect to the real wage, the Solow condition (12) implies that $\left(C_{t}^{e}-b C_{t-1}\right) /\left(C_{t}^{s}-b C_{t-1}\right)$ is fixed and depends only on the parameters $s, T$, $\xi$, and $d / \theta$. Specifically, one can show that this ratio satisfies

$$
T\left(\frac{d}{\theta}\right)(1-s \tilde{C})(\tilde{C}-1)=(1-s)\left[(T-\xi) \tilde{C}^{1+d / \theta}-T \tilde{C}\right]
$$

where $\tilde{C} \equiv\left(C_{t}^{e}-b C_{t-1}\right) /\left(C_{t}^{s}-b C_{t-1}\right)$. This result generalizes the findings of Alexopoulos (2004) to account for the impact of habit formation on wage contracts.

Although firms negotiate wage contracts every period, price contracts can last for several periods. In the spirit of Calvo (1983), I assume that a fraction $1-\chi$ of randomly selected firms adjust their nominal prices optimally in each period. Following Giannoni

\footnotetext{
${ }^{8}$ Firms take the government insurance fee and the habit variable as given when making wage decisions.
} 
and Woodford (2004), the remaining $\chi$ firms index to past inflation according to the rule $P_{t}(i)=P_{t-1}(i) \pi_{t-1}^{\gamma} \pi^{1-\gamma}$, where $\pi$ denotes steady-state gross inflation and $\pi_{t-1}$ is the inflation rate between periods $t-2$ and $t-1$. The parameter $\gamma \in[0,1]$ measures the percent of lagged inflation in the indexation rule. Let $\tilde{P}_{t}$ denote the price common to all firms that reoptimize during period $t$. Firms choose $\tilde{P}_{t}$ to maximize the present value of profits given by

$$
E_{t} \sum_{j=0}^{\infty}(\chi \beta)^{j}\left(\frac{\lambda_{t+j} / P_{t+j}}{\lambda_{t} / P_{t}}\right)\left[\frac{\tilde{P}_{t}}{P_{t+j}}\left(\prod_{\tau=0}^{j-1} \pi_{t+\tau}^{\gamma} \pi^{1-\gamma}\right)-m c_{t+j}\right] P_{t+j} Y_{t+j}(i)
$$

where $m c_{t}$ is the real marginal cost of production and the term $\beta^{j}\left(\lambda_{t+j} / P_{t+j}\right) /\left(\lambda_{t} / P_{t}\right)$ measures the family's date- $t$ nominal value of additional profits acquired at date $t+j$.

\subsubsection{The No-Shirking Condition}

The presence of unobservable effort means that the labor market can no longer be described in Walrasian terms. In the language of Shapiro and Stiglitz (1984), a "no-shirking condition" originating from the incentive compatibility constraint supplants the neoclassical labor sup-

ply curve. To derive the no-shirking condition, substitute (3) into (4) and apply the result that $\left(C_{t}^{e}-b C_{t-1}\right) /\left(C_{t}^{s}-b C_{t-1}\right)$ is constant in equilibrium to obtain

$$
(1-s)\left(\frac{\tilde{C}}{\tilde{C}-1}\right) h_{t} w_{t}=C_{t}^{e}-b C_{t-1}
$$

For constant family consumption, (15) implies a positive relationship between $w_{t}$ and $N_{t}$.

The no-shirking requirement also implies a fixed relationship between employed and unemployed consumption. Combining (3), (5), (6), and (15) yields

$$
\frac{C_{t}^{u}-b C_{t-1}}{C_{t}^{e}-b C_{t-1}}=\mu(\sigma) \equiv 1-\frac{1-\sigma}{1-s}\left(\frac{\tilde{C}-1}{\tilde{C}}\right)
$$

where $\mu$ is a scalar with an upper bound of one and increasing in $\sigma$. Because changes in $\sigma$ 
translate directly into changes in $\mu$ for fixed values of $s$ and $\tilde{C}$, the value of $\mu$ fully identifies the scope of insurance coverage. Under full insurance, $\mu(\sigma=1)=1$ and (16) collapses to $C_{t}^{u}=C_{t}^{e}$. Under partial insurance, $\mu(\sigma<1)<1$ and (16) implies $C_{t}^{u}=\mu C_{t}^{e}+(1-\mu) b C_{t-1}$.

\subsection{The Government}

The government conducts monetary policy through control of the one-period nominal interest rate $R_{t}$. Policy decisions are characterized by an empirical reaction function of the form

$$
\log \frac{R_{t}}{R}=\theta_{R} \log \frac{R_{t-1}}{R}+\left(1-\theta_{R}\right)\left[\theta_{\pi} \log \frac{\pi_{t}}{\pi}+\sum_{j=0}^{1}\left(\theta_{Y j} \log \frac{Y_{t-j}}{Y}+\theta_{w j} \log \frac{w_{t-j}}{w}\right)\right]+\varepsilon_{R, t}
$$

which calls for a gradual adjustment of $R_{t}$ to steady-state departures of current inflation, current and past output, and current and past real wages with coefficients $\left\{\theta_{\pi}, \theta_{Y 0}, \theta_{Y 1}, \theta_{w 0}, \theta_{w 1}\right\}$. The response coefficient $\theta_{R}$ captures the degree of interest rate smoothing. The purely random component of policy is summarized by the stochastic variable $\varepsilon_{R, t} \sim N\left(0, \sigma_{R}^{2}\right)$.

The reaction function (17) is similar to the one employed by Amato and Laubach (2003) in that it incorporates feedback from the real wage. ${ }^{9}$ It nests as special cases key aspects of other rules examined in previous studies. Setting $\theta_{w 0}=\theta_{w 1}=0$ transforms (17) into a variant of the Taylor (1993) rule where the interest rate responds solely to fluctuations in output and inflation. When $\theta_{Y 1}=-\theta_{Y 0}$, the government responds to movements in the growth rate of output, a variable featured prominently in the rules estimated by Ireland (2004b). I leave all of the coefficients unconstrained in this paper, thereby preserving flexibility in the way monetary policy reacts to changes in output, inflation, and the real wage.

\footnotetext{
${ }^{9}$ Their policy equation is somewhat more general than (17) because it includes additional lags of the variables appearing on the righthand side.
} 


\section{Equilibrium and Estimation Strategy}

The optimality conditions of the model along with various identity and market-clearing conditions, the laws of motion for the shocks, and the monetary policy rule form a system of nonlinear difference equations characterizing the dynamic equilibrium of the shirking model. ${ }^{10}$ When the shocks are fixed at their mean values, the difference equations jointly imply that all prices and quantities converge to a unique steady state. ${ }^{11}$ I log-linearize the difference equations around the steady state and solve the resulting system using the method developed by Klein (2000). The solution takes the general form

$$
\begin{gathered}
\mathbf{s}_{t}=\Pi \mathbf{s}_{t-1}+\Omega \varepsilon_{t}, \\
\mathbf{f}_{t}=\mathbf{U} \mathbf{s}_{t}
\end{gathered}
$$

where $\mathbf{s}_{t}$ is a vector of exogenous shocks and endogenous state variables. The vector $\varepsilon_{t}$ contains the innovations $\varepsilon_{z, t}, \varepsilon_{g, t}, \varepsilon_{a, t}, \varepsilon_{\eta, t}, \varepsilon_{h, t}$, and $\varepsilon_{R, t}$, and $\mathbf{f}_{t}$ holds the endogenous flow variables. The elements of $\boldsymbol{\Pi}$ and $\mathbf{U}$ are functions of the structural parameters, and $\boldsymbol{\Omega}$ is a selector matrix owing to the different sizes of $\mathbf{s}_{t}$ and $\varepsilon_{t}{ }^{12}$

As illustrated by Kim (2000) and Ireland (2001), a class of models with solutions of the form (18) - (19) are amenable to maximum likelihood estimation using the Kalman filtering algorithms described in Hamilton (1994, Ch. 13). With data on the model's observable variables, the Kalman filter compiles a history of innovations $\left\{\varepsilon_{t}\right\}_{t=1}^{T}$ that can be used to construct the sample likelihood function. Because the innovations depend on $\boldsymbol{\Pi}$ and $\mathbf{U}$, the structural parameters can in principle be estimated by maximizing this likelihood function. ${ }^{13}$

I estimate the parameters of the shirking model using data on consumption, investment,

\footnotetext{
${ }^{10}$ Refer to Appendix A for a comprehensive list of the model's equilibrium conditions.

${ }^{11}$ A derivation of the model's steady state equilibrium can be found in Appendix B.

${ }^{12}$ Appendix $\mathrm{C}$ contains details about the complete system of log-linear difference equations.

${ }^{13}$ Refer to Appendix D for a more detailed discussion of the estimation procedure.
} 
the real wage, inflation, and the nominal interest rate. With data on five variables, no fewer than five shocks must enter the econometric model to circumvent the stochastic singularity problem emphasized by Ruge-Murcia (2007). Preliminary attempts to estimate the model with just five shocks (i.e., neutral and investment-specific technology shocks, a preference shock, a markup shock, and a policy shock) were successful under a partial insurance arrangement. Under full insurance, however, the covariance matrix of the data became singular for the following reason. The no-shirking condition (15) becomes $(1-s)(\tilde{C} /(\tilde{C}-1)) h_{t} w_{t}=C_{t}-b C_{t-1}$ when $\mu=1$, implying an exact deterministic relationship between consumption and the real wage in the absence of shocks to hours worked. Using data on both variables necessarily renders the model stochastically singular. Thus, I assume that the shift length varies exogenously so that the partial and full insurance models can be estimated using the same data. Temporal variation in hours worked drives a stochastic wedge between consumption and the real wage, sidestepping the singularity problem that emerges in the presence of complete risk sharing. ${ }^{14}$

The key parameters of interest are those governing the labor market and the risk sharing arrangement. Alexopoulos (2004) and Alexopoulos (2007) use an exactly identified GMM strategy to form inferences about their values. The central estimate in both studies is the ratio $d / \theta$ appearing in the incentive compatibility constraint (equation (11) in this paper). To identify this ratio, several assumptions are made about the other parameters affecting labor supply. Specifically, $T$ and $\xi$ are calibrated to match the time resources available to workers every quarter, and $\tilde{C}$ is chosen to match the estimated decline in food consumption resulting from unemployment reported by Gruber (1997). With fixed values for $T$, $\xi$, and $\tilde{C}$ and an estimate of $d / \theta$, the value of $s$ is determined from the Solow condition (equation (13) in this paper). All five parameters jointly determine the average employment rate $N$.

\footnotetext{
${ }^{14} \mathrm{An}$ alternative strategy would be to augment the observable variables with a vector of measurement errors (e.g., McGratten, 1994; Hall, 1996; Ireland, 2004a). I find this approach less appealing because measurement errors carry no structural interpretation and basically absorb specification error.
} 
A potential drawback of this strategy is that it forces the researcher to make assumptions regarding the scope of the insurance program before estimation. In both studies, two sets of estimates are obtained by placing competing restrictions on the risk sharing parameter $\mu$, that is, on the equilibrium value of $C_{t}^{u} / C_{t}^{e}$. One case considers full insurance by restricting $\mu=1$. The other case considers a specific amount of partial insurance in which $\mu=1 / \tilde{C}$. No other risk sharing arrangements are considered during the course of estimation. ${ }^{15}$

I take a different approach here by leaving $\mu$ unrestricted and allowing the data to ascertain the true relationship between $C_{t}^{u}$ and $C_{t}^{e}$. One advantage of this strategy is that the researcher need not make additional assumptions regarding the values of $T, \xi, \tilde{C}, d / \theta$, or $s$. It turns out that $s$ and $\tilde{C}$ only appear as the ratio $((1-s) \tilde{C}) /(\tilde{C}-1)$, which can be expressed as a function of parameters that are either estimated directly or calibrated prior to estimation. Moreover, $T, \xi$, and $d / \theta$ serve only to determine the steady-state employment rate $N$. I choose to insert $N$ directly into the linearized model rather than assign values to $T, \xi$, and $d / \theta$ because there is ample evidence about the size of the former but only sparse information about appropriate values for the latter.

Most of the remaining parameters are estimated with quarterly US data ranging from 1959:II to 2005:IV. Consumption is measured by real personal consumption expenditures, and investment is real gross private domestic investment. To express them in per capita terms, I divide each series by the civilian noninstitutional population, age 16 and over. The real wage corresponds to real compensation per hour in the nonfarm business sector. Inflation is the log first difference of the GDP deflator, and the nominal interest rate is measured by the log of the gross return on three-month Treasury bills at a quarterly rate. All data except for the interest rate are seasonally adjusted.

To make the data conformable with the model, I subtract the sample mean from observations of inflation and the interest rate under the assumption that both series are stationary.

\footnotetext{
${ }^{15}$ The interpretation of $\mu$ is slightly different in this paper due to the presence of habit formation.
} 
Consumption, investment, and the real wage, exhibit separate positive trends, reflecting the long-run balanced growth of the US economy. Following Rabanal and Rubio-Ramirez (2005), I regress the logarithms of all three against a constant, a linear time trend, and a quadratic time trend. The resulting ordinary least squares residuals are used for estimation.

\section{Empirical Results}

\subsection{Maximum Likelihood Estimates}

Some parameters are fixed prior to estimation because they are either weakly identified in the data or external information about their values is available. The discount factor $\beta$ is set to 0.9955 to ensure an annualized mean real interest rate equal to the ratio of the sample averages of inflation and the nominal interest rate. Using evidence from the National Income and Product Accounts, I set the capital share parameter $\alpha=0.36$. Absent data on the capital stock, I fix the depreciation rate $\delta=1.1^{1 / 4}-1$ so that capital depreciates at a rate of 10 percent per annum. Two other parameters that suffer weak identification are the steady-state markup $\eta$ and the average employment rate $N$. I set $\eta=0.20$ to deliver an average markup of 20 percent (e.g., Basu and Fernald, 1997), and I fix $N=0.941$ to match the mean employment rate over the sample period. Finally, initial attempts to estimate the price adjustment term $\chi$ consistently returned values that point to extremely high nominal rigidity. As a result, I set $\chi=0.80$, implying that prices are reset optimally every 5 quarters on average. This value is greater than, but not inconsistent with, recent microeconomic evidence on the frequency of price changes (e.g., Nakamura and Steinsson, 2008). ${ }^{16}$

\footnotetext{
${ }^{16}$ The price adjustment coefficient is notoriously difficult to estimate in DSGE models using likelihoodbased methods. Ireland (2004b) holds fixed this parameter during estimation because it repeatedly converged to unreasonable values when left unrestricted. Applying Bayesian priors that effectively penalize these areas of the parameter space, Smets and Wouters (2005) and Levin, Onatski, Williams, and Williams (2005) obtain estimates that actually exceed the value used in this paper.
} 
Table 1 displays the point estimates and standard errors of the remaining parameters. ${ }^{17}$ Panel A presents estimates for the full sample, while panel B presents estimates for a subsample starting in 1979:III. ${ }^{18}$ Two sets of estimates are reported for both samples. The first set considers partial insurance by leaving the risk sharing parameter $\mu$ unconstrained. The second set examines the case of full insurance by restricting $\mu=1$.

For the full sample, estimates of the capital adjustment cost parameter $\phi$ are large and statistically significant regardless of the insurance plan. The estimate of habit formation $b$ is 0.25 under partial insurance and 0.36 under full insurance. Both estimates are smaller than the ones reported by Fuhrer (2000) and Boldrin, Christiano, and Fisher (2001), but they are close to the values obtained by Levin et al. (2005) and Ireland (2007). Estimates of the inflation indexation parameter $\gamma$ are sensitive to the assumed nature of risk sharing. In the unrestricted model, $\gamma$ approaches the upper bound of the allowable parameter space. With complete risk sharing, however, $\gamma$ converges to zero during the course of estimation. ${ }^{19}$

Concerning the policy rule, estimates of the smoothing coefficient $\theta_{R}$ are large and statistically significant, reflecting the Federal Reserve's tendency to adjust interest rates gradually in response to shocks. Estimates of $\theta_{\pi}, \theta_{Y 0}$, and $\theta_{Y 1}$ indicate a greater historical emphasis on stabilizing inflation than real output. Interestingly, similarities between $\theta_{Y 0}$ and $\theta_{Y 1}$ suggest that policy responds more to fluctuations in the growth rate of output than to its absolute level. Both point estimates are statistically different from zero, but their sum is not. The coefficients on current and lagged real wages are smaller and statistically insignificant at standard levels. Finally, comparing estimates across both versions of the model reveals that the long-run responses to inflation and output growth are larger under partial insurance.

\footnotetext{
${ }^{17}$ Robust standard errors are obtained by taking the square roots of the diagonal elements of the variancecovariance matrix proposed by White (1982).

${ }^{18}$ This date corresponds to the appointment of Paul Volcker to Chairman of the Federal Reserve and is an event that is commonly believed to have marked the beginning of a regime shift in US monetary policy.

${ }^{19}$ To avoid boundary problems during estimation, I use a logistical transformation $\gamma=1 /(1+\exp (10 \times \tilde{\gamma}))$. Sample log-likelihood is maximized over $\tilde{\gamma}$, while standard errors for $\gamma$ are obtained using the Delta method.
} 
Turning next to the exogenous shocks, estimates of $\rho_{z}, \rho_{a}$, and $\rho_{g}$ indicate that neutral and investment-specific technology shocks as well as preference shocks are highly persistent. Levin et al. (2005) and Smets and Wouters (2007) also report persistent technology and preference shocks. Estimates of the standard deviations are also statistically significant and not greatly affected by the prevailing insurance arrangement. There is one exception. The estimate of $\sigma_{h}$ is 0.0075 under partial insurance and 0.03 under full insurance. With complete risk sharing, the shirking model evidently requires large shocks to hours worked in order to fit the data. Given that most of the variation in total hours occurs along the employment margin, I take this finding as evidence in favor of partial insurance.

Finally, the estimate of the risk sharing parameter $\mu$ is 0.48 , implying that consumption less the habit stock for unemployed members is about one-half of what it is for employed members. To make a direct comparison with the insurance schemes considered in Alexopoulos (2004) and Alexopoulos (2007), it is necessary to determine what $\mu$ reveals about the relative consumption of the unemployed $C_{t}^{u} / C_{t}^{e}$. Both studies fix this ratio, which is constant in equilibrium, equal to 0.78 prior to estimation, ensuring that consumption declines by 22 percent when unemployed. Unfortunately, it is impossible to derive a parallel ratio for this model because the presence of habit formation makes $C_{t}^{u} / C_{t}^{e}$ time varying. In the absence of shocks, however, $C_{t}^{u} / C_{t}^{e}$ eventually converges to a steady-state level given by

$$
\frac{C^{u}}{C^{e}}=\frac{\mu(1-b)+[N+(1-N) \mu] b}{(1-b)+[N+(1-N) \mu] b} .
$$

The estimates of $\mu$ and $b$ jointly imply an estimate of $C^{u} / C^{e}$ equal to 0.61 with a corresponding standard error of 0.03. The interpretation is that unemployed members consume on average about three-fifths of what employed members consume every period. Formal estimates of the degree of risk sharing are, therefore, smaller than, but not totally inconsistent 
with, values commonly assumed in previous studies. ${ }^{20}$

To determine if the model with partial insurance can better account for the time series behavior of the data, I conduct a likelihood ratio test of the restriction imposed by full insurance. The likelihood ratio statistic is formed by subtracting the restricted value of the maximized log likelihood function from its unrestricted counterpart and multiplying the difference by two. It is asymptotically distributed as a chi-square random variable with one degree of freedom. Table 1 reports a value of the maximized log likelihood function of 3143.05 in the unrestricted model and 3079.74 in the restricted model. Under the null hypothesis that $\mu=1$, the test statistic is 126.62 with a $p$-value less than 0.001 . Thus, incorporating limited risk sharing statistically improves the ability of the shirking model to fit the data.

As a robustness check, I reestimate the model using a subsample that begins in 1979:III. Numerous studies conclude that the stance of monetary policy changed considerably following the appointment of Paul Volcker to Chairman of the Federal Reserve (e.g., Clarida, Galí, and Gertler, 2000). As evidence of a regime shift, they point to structural breaks in the estimated coefficients of policy rules like (17) when the sample is divided into disjoint subsamples around 1980. It remains to be seen whether the parameters of the model, especially those governing the insurance arrangement, are significantly altered when reestimated over a sample period that coincides with a more stable monetary regime.

The estimates of $\theta_{\pi}, \theta_{Y 0}$, and $\theta_{Y 1}$ reported in panel $\mathrm{B}$ are indeed larger than those from the full sample, indicating a stronger response to variations in inflation and output growth during the post-1979 period. Most of the remaining estimates are not greatly affected by the choice of sample period. The exceptions include capital adjustment costs $\phi$ and the standard deviation of investment shocks $\sigma_{a}$. Estimates of $\phi$ and $\sigma_{a}$ for the post-1979 subsample are significantly larger than their full sample counterparts. Ireland (2003) also reports rising adjustment costs and larger investment shocks after the period ending in 1979. Estimates

\footnotetext{
${ }^{20} \mathrm{~A}$ simple Wald test of the null hypothesis that $C^{u} / C^{e}=0.78$ is rejected at standard significance levels.
} 
from the more recent sample also tell a familiar story about the risk sharing behavior of consumers. The estimates of $\mu(0.40)$ and $b(0.30)$ jointly imply a steady-state consumption ratio $C^{u} / C^{e}$ equal to 0.58 with a standard error of 0.05 . Accounting for the likely regime shift in monetary policy that occurred after 1979 evidently has little effect on the degree of risk sharing implied by the data.

\subsection{Second Moment Properties}

In this section I assess the role of partial insurance in capturing some important features of the US business cycle. Specifically, I calculate a set of moments implied by the estimated models and compare them to ones obtained from the data. The full information approach used here does not focus exclusively on replicating this small set of statistics, but rather on matching the broad aspects of the data embodied by the likelihood function. To see which features are better explained by the unrestricted model, I examine what the parameter estimates imply for these commonly studied statistics.

Table 2 reports three sets of statistics. The first group contains the standard deviations of the logarithms of detrended $C_{t}$, detrended $I_{t}$, detrended $w_{t}, N_{t}, \pi_{t}$, and $R_{t}$. Each one is divided by the standard deviation of the logarithm of detrended $Y_{t}$, defined in the models and the data as the sum of consumption and investment. The second set includes contemporaneous correlations between the first six variables and output. Correlations with the real wage form the third set. Panel A presents statistics calculated from the data. ${ }^{21}$ Panels B and $\mathrm{C}$ report statistics for the partial and full insurance models, respectively. The moments in panel $\mathrm{D}$ are those implied by the unrestricted model with full insurance imposed after estimation. They are generated by setting $\mu=1$ while preserving all other estimates from the partial insurance model.

The relative volatility of consumption in the partial insurance model matches closely

\footnotetext{
${ }^{21}$ The employment rate is calculated in the data as civilian employment divided by the civilian labor force.
} 
the realized volatility in the data. Alternatively, the restricted, full insurance model comes closest to matching the standard deviation of investment. Echoing the results of Alexopoulos (2004), the partial insurance model accounts for the observed volatility of the real wage relative to output. The full insurance model counterfactually predicts higher wage volatility than output volatility. Finally, all three models overstate employment volatility but explain well the low variation in inflation and the nominal interest rate.

The partial insurance model is unambiguously more successful at matching the correlations with output. All have the correct sign and magnitude and are closer to the ones obtained from the data. Similar to Alexopoulos (2004), partial insurance reduces the correlation between the real wage and output and increases the correlation with employment. It also helps capture the small positive correlation between inflation and output and the small negative correlation with the nominal interest rate. The full insurance models overstate both and falsely predict the sign of the latter.

The results are mixed regarding the covariation of wages. Under both insurance schemes, the model exaggerates the positive correlation with consumption. By contrast, the partial insurance model understates, whereas the full insurance models overstate, the correlation with investment. All three match closely the correlation with inflation, but they fail to predict the negative correlation with the interest rate. Finally, only the partial insurance model is able to account for the Dunlop-Tarshis observation that real wages move countercyclically with employment (e.g., Christiano and Eichenbaum, 1992). ${ }^{22}$

Figure 1 plots the vector autocorrelation functions for the logarithms of detrended $Y_{t}$, detrended $w_{t}, \pi_{t}$, and $R_{t}$ as implied by the data and the models. Following Fuhrer and Moore (1995), the autocorrelations for the data are computed from an unrestricted, fourth-order vector autoregression.

\footnotetext{
${ }^{22}$ The restricted, full insurance model actually comes closest to matching the employment-wage correlation in the data of 0.11 .
} 
It is clear that the partial insurance model is better at replicating most of the key autocorrelations involving the real wage. The degree of wage persistence, as measured by correlations between current and lagged real wages, is larger under partial insurance. The half-life of this function is about five years in the partial insurance model but only two years in the restricted, full insurance model. Limited risk sharing also helps explain the cross correlations with output. The unrestricted model matches closely the positive and diminishing correlation between current output and the real wage one to two years in the past. It also captures the positive, hump-shaped correlation between the current real wage and past output, with the peak occurring at a two-year lag.

The partial insurance model is also better at matching the cross correlations between nominal and real variables. For example, it more accurately reproduces the true correlation function between output and inflation emphasized by Galí and Gertler (1999). The model correctly predicts the negative and declining correlation between current output and inflation one year in the past. It also captures the positive and rising correlation between current inflation and past output, with the maximum correlation occurring at a lag of two years.

The partial insurance model generates a more consistent lead-lag relationship between output and the nominal interest rate. Limited risk sharing helps capture, albeit a small one, the "inverted leading indicator" role (e.g., King and Watson, 1996), that is, the negative correlation between output and lagged interest rates found in the data. The unrestricted model also predicts remarkably well the sign and magnitude of the correlation between the interest rate and past output up to a lag of five years.

While it generates a visible improvement in overall fit, incorporating partial insurance does not enhance the model's performance in every dimension. Nonetheless, in the areas where the partial insurance model dominates, the restricted and unrestricted full insurance models have very similar correlation patterns, indicating that it is indeed the insurance mechanism that is chiefly responsible for improving the fit of the model. 


\subsection{Variance Decompositions}

In this section I evaluate the ability of the shirking model to correctly identify the underlying sources of economic fluctuations observed in the data. To that end, I compare forecast error variance decompositions of the partial insurance model with those from the restricted, full insurance model. The goal is to determine in what way, and to what extent, limited risk sharing aids in matching the decompositions found in other studies that estimate the contributions of the same shocks appearing in this paper. For the partial and full insurance models, Tables 3 and 4 decompose the variances of output, consumption, investment, the real wage, employment, inflation, and the nominal interest rate into shares attributed to each of the six orthogonal shocks described above. Panel A reports conditional variances at a one-year forecast horizon, panel B a three-year horizon, and panel C a ten-year horizon.

I first consider the contribution of monetary shocks. Using a structural VAR, Christiano, Eichenbaum, and Evans (2005) show that policy shocks have a modest effect on output fluctuations but a small impact on inflation and the real wage. Meanwhile, they have a sizeable effect on interest rate variability in the short run that diminishes at longer horizons.

A comparison of Tables 3 and 4 reveals that policy shocks contribute less to output movements in the unrestricted model. At a one-year horizon, they account for 6 percent of output variation under partial insurance but 9 percent under full insurance. Similarly, their contribution to real wage and inflation variability is smaller in the presence of limited risk sharing. Policy shocks are responsible for less than 3 percent of inflation variance after one year in the partial insurance model but more than 20 percent in the full insurance model. The partial insurance model also attributes a greater share of interest rate variability to policy shocks than the full insurance model. At a one-year horizon, they account for approximately 25 percent of interest rate fluctuations in the former but 15 percent in the latter.

Turning next to technology shocks, Fisher (2006) demonstrates, using an identified VAR, that neutral and investment-specific shocks jointly explain about 60 percent of output fluctu- 
ations at a forecast horizon of one year and 80 percent after eight years. From the perspective of a medium-scale equilibrium model along the lines of Smets and Wouters (2003), Justiniano, Primiceri, and Tambalotti (2008) find that investment-specific shocks alone account for about 50 percent of the variance of output and 80 percent of the variance of investment at business cycle frequencies. Neutral shocks, on the other hand, explain 25 percent of output volatility and less than 10 percent of investment volatility.

The decompositions indicate that the unrestricted model is more consistent with these broad findings. At a forecast horizon of one year, neutral and investment-specific technology shocks together explain about 65 percent of output fluctuations in the partial insurance model but almost 90 percent in the full insurance model. The joint contributions rise to about 80 and 95 percent, respectively, at a ten-year horizon. At a three-year horizon, investmentspecific shocks alone account for approximately 50 percent of the variance of output and over 75 percent of the variance of investment in the partial insurance model. The full insurance model attributes less than 20 percent of output variability and only 55 percent of investment variability to this shock. Neutral technology shocks explain 28 (75) percent of output fluctuations and 6 (34) percent of investment fluctuations in the partial (full) insurance model at the same forecast horizon.

Regarding cost-push shocks, Ireland (2004b), in the context of an estimated sticky-price model, attributes to them more than 60 percent of the movements in inflation at all forecast horizons. Similarly, cost-push shocks account for 15 to 30 percent of the variance of the nominal interest rate between one and ten years.

The shirking model tells a very different story about the importance of cost-push shocks depending on the nature of unemployment insurance. Across all horizons, they account for more than 50 percent of inflation variability under partial insurance but less than 7 percent under full insurance. Cost-push shocks are also a dominant source of interest rate volatility in the partial insurance model, accounting for over 40 percent in the short run and 30 percent 
in the long run. Alternatively, they have a trivial effect on interest rates in the full insurance model, contributing less than 1 percent to the variance at all horizons.

Finally, contributions of shocks to hours worked and the time rate of preference are broadly similar in both models. There is one obvious difference, however, that favors partial insurance. Shocks to hours worked in the full insurance model are the largest contributor to short-run changes in the real wage, explaining 66 percent of the total variation at a one-year horizon. By contrast, they explain only 9 percent in the partial insurance model. Real wages are instead driven primarily by neutral technology shocks, which account for 52 percent of the total variation in the short run. Justiniano et al. (2008) find that neutral technology shocks account for nearly 40 percent of real wage variability at business cycle frequencies.

\subsection{The Importance of Capturing Wage Dynamics}

The preceding analysis makes clear that partial insurance strengthens the broad empirical performance of the model. It also highlights several distinct features of the data that cannot be reconciled with full insurance. But what is it about the nature of incomplete risk sharing that gives rise to these improvements? To address this question and gain further insight into the model, below I derive a log-linear equation for the equilibrium real wage. In doing so, I uncover an interesting employment effect that emerges only under partial insurance. This effect works to dampen the adjustment of wages to certain shocks while amplifying the response to others. The result is a simple empirical relationship that is more suitable for capturing the persistence and co-movement of real wages observed in the data.

To derive an expression for the real wage, substitute into the no-shirking condition (15) the log-linear approximations of the risk-sharing condition (16) and the equation defining average consumption across family members. After some rearranging, the linearized no- 
shirking condition can be written as

$$
\hat{w}_{t}=\frac{1}{1-b} \hat{C}_{t}-\frac{b}{1-b} \hat{C}_{t-1}-\tau \hat{N}_{t}-\hat{h}_{t}
$$

where $\tau=N(1-\mu) /[N(1-\mu)+\mu]$ and $\hat{x}_{t}$ denotes the logarithmic deviation of a variable $x_{t}$ from its steady state value.

Two aspects of (20) reveal the source of improved wage dynamics under partial insurance. First, the direct impact of employment fluctuations, as measured by $\tau$, depend on the scope of the insurance policy. Specifically, $\tau$ is a positive and decreasing function of the risk-sharing parameter $\mu$. In the limiting case of full insurance $(\mu=1)$, the employment effect disappears altogether as $\tau=0$. Second, note that employment enters (20) with a negative sign. Shocks that tend to boost wages will be partially offset if those shocks also expand employment. They will be amplified if employment contracts. It turns out that this employment effect helps reduce the volatility of real wages as well as the correlation between wages and output.

To understand why the no-shirking condition implies an inverse relationship between the labor input and the real wage, consider the effects of a unit rise in employment. Under partial insurance, the average marginal utility of consumption across members will fall because the utility function is concave and $C_{t}^{e}>C_{t}^{u}$. For a fixed average marginal utility of wealth, families will reduce average consumption, which lowers the wage necessary to satisfy the incentive compatibility constraint. With full insurance, an increase in employment has no impact on average marginal utility since all members consume equal quantities.

Evidence of the employment effect appears in Figure 2, which graphs the response of the model variables to the structural shocks. The solid line in each panel illustrates the response profile in the unrestricted model with partial insurance. For comparison, the dotted line measures the response in the same model with full insurance imposed after estimation. ${ }^{23}$

\footnotetext{
${ }^{23}$ Not shown in the figure is the response to the labor supply shock affecting the hours margin because the wage response is identical for the two models considered.
} 
Consider first the impact of a one standard deviation (negative) shock to monetary policy. The nominal interest rate falls, boosting consumption and output, which, in turn, puts upward pressure on the real wage. Because it also increases employment, the real wage adjustment under partial insurance is small. A similar pattern emerges following a preference shock and, in the opposite direction, a price markup shock. The muted response of wages under partial insurance helps the shirking model capture the low relative volatility found in the data, and it weakens the high correlation with output that would otherwise occur under full insurance. The sluggish wage response to a monetary shock, through its impact on marginal cost, also leads to a more inertial adjustment of inflation and greater persistence in the path of output under partial insurance. This result is in line with the evidence reported in Christiano et al. (2005) and others.

Turning next to the investment-specific technology shock, the consumption response is initially negative as families take advantage of higher returns to capital. The contemporaneous increase in employment causes the decline in real wages to be greater under partial insurance. A strong countercyclical response to investment-specific shocks, in turn, helps the model explain the small wage-output and wage-employment correlations observed in the data. Note also that lower real wages persuade firms to keep employment demand high for several periods. Persistent employment, through its effect on the no-shirking condition, ensures that wages will readjust more gradually under partial insurance. Thus, although wages do not exhibit any intrinsic persistence in the model, they inherit considerable persistence from the employment series when risk sharing is incomplete. This feature allows the partial insurance model to generate greater overall wage persistence as reflected in the autocorrelation function.

Figure 3 evaluates the model's goodness of fit for the real wage by plotting one-step-ahead forecasts against the actual data. Two different series of wage predictions are generated. One is from the unrestricted model with partial insurance, while the other is from the restricted, 
full insurance model. The partial insurance model tracks well the dynamics of real wages over the sample. The correlation between the observed and predicted real wage is 0.96 . The forecasting accuracy of the full insurance model is considerably worse. It is unable to capture the gradual decline in the real wage from 1975-1995, nor is it able to explain the rapid ascent starting in 1997. The correlation between the observed and predicted real wage in this case is only 0.54 .

\section{Concluding Remarks}

In this paper I estimate a sticky-price model that gives prominence to a shirking, efficiencywage view of the labor market along the lines of Alexopoulos (2004). Central to the model is an insurance mechanism that allows, but does not require, agents to fully insure each other against employment risk. The principle objectives of this study are to determine the extent of risk sharing implied by the data and to assess the importance of the insurance mechanism for improving the fit of the model.

Maximum likelihood estimates reveal that the data prefer an arrangement in which individuals are only partially insured. Likelihood ratio tests formally reject the hypothesis of full insurance. Less formal comparisons based on an assortment of key second moments provide additional evidence in favor of limited risk sharing. With partial insurance, for example, the model is better at capturing many volatilities and correlations observed in the data, and it also improves the fit of several key autocorrelation functions involving the real wage.

Even though partial insurance improves the model's empirical performance along numerous dimensions, some potential concerns remain that warrant further consideration. First, the model generates too much employment volatility. This problem could be addressed by incorporating data on the employment rate into the estimation procedure while simultaneously modifying the firm's decision problem to include labor adjustment costs. Second, the 
predicted co-movement between the real wage and the nominal interest rate is inconsistent with the data and invariant to the scope of insurance coverage. This fact suggests that the shirking model lacks the right economic machinery needed to capture the true dynamic relationship reflected in the sample. A more sophisticated model featuring sticky nominal wages or limited participation could possibly correct this deficiency. Third, a more appealing model would also allow for joint inference about the extent of risk sharing and the magnitude of nominal rigidity. Due to limitations in the data, I am presently unable to identify the key adjustment probability that governs the degree of price stickiness. Recent studies have experienced some success in identifying this probability by using Bayesian estimation techniques. I believe that confronting these issues is an important task but properly the business of future research. 


\section{Appendix A. General Equilibrium Conditions}

- Average marginal utility of consumption

$$
X_{t}=g_{t}\left(\frac{N_{t}}{C_{t}^{e}-b C_{t-1}}+\frac{1-N_{t}}{C_{t}^{u}-b C_{t-1}}\right)
$$

- Euler equation for family-purchased consumption

$$
\lambda_{t}=X_{t}-\beta b E_{t} X_{t+1}
$$

- Euler equation for bond holdings

$$
\lambda_{t}=\beta R_{t} E_{t}\left(\frac{\lambda_{t+1}}{\pi_{t+1}}\right)
$$

- Euler equation for investment ${ }^{24}$

$$
1=q_{t}\left[a_{t}-\phi\left(\frac{I_{t}}{K_{t}}-\delta\right)\right]
$$

- Euler equation for capital

$$
\lambda_{t} q_{t}=\beta E_{t} \lambda_{t+1} r_{t+1}^{k}+\beta E_{t} \lambda_{t+1} q_{t+1}\left[1-\delta-\frac{\phi}{2}\left(\frac{I_{t+1}}{K_{t+1}}-\delta\right)^{2}+\phi\left(\frac{I_{t+1}}{K_{t+1}}-\delta\right) \frac{I_{t+1}}{K_{t+1}}\right]
$$

- Law of motion for capital

$$
K_{t+1}=(1-\delta) K_{t}-\frac{\phi}{2}\left(\frac{I_{t}}{K_{t}}-\delta\right)^{2} K_{t}+a_{t} I_{t}
$$

- No-shirking condition

$$
(1-s)\left(\frac{\tilde{C}}{\tilde{C}-1}\right) h_{t} w_{t}=C_{t}^{e}-b C_{t-1}
$$

- Consumption risk-sharing condition

$$
C_{t}^{u}=\mu C_{t}^{e}+(1-\mu) b C_{t-1}
$$

- Average consumption

$$
C_{t}=N_{t} C_{t}^{e}+\left(1-N_{t}\right) C_{t}^{u}
$$

\footnotetext{
${ }^{24}$ The variable $q_{t}$ is the lagrange multiplier for the capital accumulation equation.
} 
- Aggregate resource constraint

$$
Y_{t}=C_{t}+I_{t}
$$

- Marginal product of capital ${ }^{25}$

$$
r_{t}^{k}=\alpha m c_{t} z_{t} K_{t}^{\alpha-1}\left(N_{t} e h\right)^{1-\alpha}
$$

- Marginal product of labor

$$
h_{t} w_{t}=(1-\alpha) m c_{t} z_{t} K_{t}^{\alpha}\left(N_{t} e h\right)^{-\alpha} e h
$$

- Aggregate production function ${ }^{26}$

$$
Y_{t} \Delta_{t}=z_{t} K_{t}^{\alpha}\left(N_{t} e h\right)^{1-\alpha}
$$

- Aggregate profit equation ${ }^{27}$

$$
D_{t}=\left(1-m c_{t} \Delta_{t}\right) Y_{t}
$$

- Equilibrium family consumption

$$
C_{t}^{f}=C_{t}-h_{t} w_{t} N_{t}
$$

- Monetary policy rule

$$
\log \frac{R_{t}}{R}=\theta_{R} \log \frac{R_{t-1}}{R}+\left(1-\theta_{R}\right)\left[\theta_{\pi} \log \frac{\pi_{t}}{\pi}+\sum_{j=0}^{1}\left(\theta_{Y j} \log \frac{Y_{t-j}}{Y}+\theta_{w j} \log \frac{w_{t-j}}{w}\right)\right]+\varepsilon_{R, t}
$$

- Aggregate price index ${ }^{28}$

$$
1=(1-\chi) P_{t}^{*-\frac{1}{\eta_{t}}}+(1-\chi) \sum_{j=1}^{\infty} \chi^{j}\left[P_{t-j}^{*} \prod_{\tau=0}^{j-1}\left(\frac{\pi_{t-\tau-1}^{\gamma} \pi^{1-\gamma}}{\pi_{t-\tau}}\right)\right]^{-\frac{1}{\eta_{t}}}
$$

- Price dispersion

$$
\Delta_{t}=(1-\chi) P_{t}^{*-\frac{1+\eta_{t}}{\eta_{t}}}+(1-\chi) \sum_{j=1}^{\infty} \chi^{j}\left[P_{t-j}^{*} \prod_{\tau=0}^{j-1}\left(\frac{\pi_{t-\tau-1}^{\gamma} \pi^{1-\gamma}}{\pi_{t-\tau}}\right)\right]^{-\frac{1+\eta_{t}}{\eta_{t}}}
$$

\footnotetext{
${ }^{25}$ The product of effort and hours worked is constant in equilibrium and given by $e h=T-\xi-T \tilde{C}^{-d / \theta}$. ${ }^{26}$ The measure of price dispersion resulting from sticky prices is given by $\Delta_{t}=\int_{0}^{1}\left(\frac{P_{t}(i)}{P_{t}}\right)^{-\frac{1+\eta_{t}}{\eta_{t}}} d i$.

${ }^{27}$ Total real profit from ownership of all firms is given by $D_{t}=\int_{0}^{1} D_{t}(i) d i$.

${ }^{28}$ The relative contract price chosen by all firms reoptimizing at date $t$ is given by $P_{t}^{*}=\tilde{P}_{t} / P_{t}$.
} 
- Euler equation for the optimal relative contract price

$$
\begin{gathered}
E_{t} \sum_{j=0}^{\infty}(\chi \beta)^{j} \lambda_{t+j} Y_{t+j} \frac{1+\eta_{t+j}}{\eta_{t+j}} P_{t}^{*^{-}} \frac{1+\eta_{t+j}}{\eta_{t+j}}\left(\prod_{\tau=1}^{j} \frac{\pi_{t+\tau-1}^{\gamma} \pi^{1-\gamma}}{\pi_{t+\tau}}\right)^{-\frac{1+\eta_{t+j}}{\eta_{t+j}}} m c_{t+j}= \\
E_{t} \sum_{j=0}^{\infty}(\chi \beta)^{j} \lambda_{t+j} Y_{t+j} \frac{1}{\eta_{t+j}} P_{t}^{*-\frac{1}{\eta_{t+j}}}\left(\prod_{\tau=1}^{j} \frac{\pi_{t+\tau-1}^{\gamma} \pi^{1-\gamma}}{\pi_{t+\tau}}\right)^{-\frac{1}{\eta_{t+j}}}
\end{gathered}
$$

\section{Appendix B. Steady State Equilibrium}

In this section I derive the deterministic steady state equilibrium of the shirking model. A box around an equation indicates that the term on the lefthand side is a function of known estimated or calibrated structural parameters and possibly variables determined at an earlier stage. The boxed equations are written in the order needed to obtain the steady state numerically. The numbers to the left of the boxes indicate which general equilibrium equation from the previous section the steady state condition corresponds to. Boxed equations with multiple numbers on the lefthand side are obtained by combining the relevant steady state conditions already determined.

$$
\begin{aligned}
& \text { (A.3) } \beta=\frac{\pi}{R} \\
& \text { (A.6) } \frac{I}{K}=\delta \\
& \text { (A.4) } q=1
\end{aligned}
$$

$$
r^{k}=\beta^{-1}-1+\delta
$$

(A.17) $P^{*}=1$

(A.18) $\Delta=1$ 


$$
\begin{aligned}
& (\mathrm{A} .19) \quad m c=(1+\eta)^{-1} \\
& \text { (A.11) } \frac{K}{N e h}=\left(\frac{r^{k}}{\alpha m c z}\right)^{\frac{1}{\alpha-1}} \\
& \text { (A.12) } h w=(1-\alpha) m c z\left(\frac{K}{N e h}\right)^{\alpha} e h \\
& \text { (A.14) } \frac{D}{Y}=1-m c \\
& \text { (A.8) } C^{u}=\mu C^{e}+(1-\mu) b C \\
& \text { (A.7) } C^{e}=(1-s)\left(\frac{\tilde{C}}{\tilde{C}-1}\right) h w+b C \\
& \text { (A.9) } C=\left(\frac{1}{1-b}\right)(1-s)\left(\frac{\tilde{C}}{\tilde{C}-1}\right) h w[N+(1-N) \mu] \\
& \text { (A.13) } Y=z\left(\frac{K}{N e h}\right)^{\alpha} N e h \\
& (\mathrm{~A} .10) \quad(1-s)\left(\frac{\tilde{C}}{\tilde{C}-1}\right)=\frac{(1-b)\left[1-\frac{\delta \alpha m c}{r^{k}}\right] N}{(1-\alpha) m c[N+(1-N) \mu]} \\
& \text { (B.2) (B.14) } \frac{I}{Y}=\frac{\delta \alpha m c}{r^{k}} \\
& \text { (B.9) (B.13) (B.14) } \frac{C}{Y}=1-\frac{I}{Y} \\
& \text { (B.9) (B.12) (B.14) (B.15) (B.16) } \frac{C^{e}}{C}=\left(\frac{1-b}{N+(1-N) \mu}\right)+b \\
& \text { (B.11) (B.18) } \frac{C^{u}}{C}=\mu\left(\frac{1-b}{N+(1-N) \mu}\right)+b \\
& \text { (A.1) } X C=\frac{N}{\left(C^{e} / C\right)-b}+\frac{1-N}{\left(C^{u} / C\right)-b} \\
& \text { (A.2) } \lambda C=(1-\beta b) X C
\end{aligned}
$$




\section{Appendix C. The Complete Linearized Model}

- Linearizing the average marginal utility of consumption (A.1) gives

$$
\begin{array}{r}
\frac{1-(1-\mu) N}{\left(C^{u} / C\right)-b}\left(\hat{X}_{t}-\hat{g}_{t}\right)=\frac{-(1-\mu) N}{\left(C^{u} / C\right)-b} \hat{N}_{t}-N\left(\frac{C^{e} / C}{\left(\left(C^{e} / C\right)-b\right)^{2}}\right) \hat{C}_{t}^{e} \\
-(1-N)\left(\frac{C^{u} / C}{\left(\left(C^{u} / C\right)-b\right)^{2}}\right) \hat{C}_{t}^{u}+\left(\frac{N}{\left(\left(C^{e} / C\right)-b\right)^{2}}+\frac{1-N}{\left(\left(C^{u} / C\right)-b\right)^{2}}\right) b \hat{C}_{t-1}
\end{array}
$$

- Linearizing the family-consumption Euler equation (A.2) gives

$$
(1-\beta b) \hat{\lambda}_{t}=\hat{X}_{t}-\beta b E_{t} \hat{X}_{t+1}
$$

- Linearizing the Euler equation for bond holdings (A.3) gives

$$
\hat{\lambda}_{t}=\hat{R}_{t}+E_{t}\left(\hat{\lambda}_{t+1}+\hat{\pi}_{t+1}\right)
$$

- Linearizing the investment Euler equation (A.4) gives

$$
\hat{q}_{t}+\hat{a}_{t}=\phi \delta\left(\hat{I}_{t}-\hat{K}_{t}\right)
$$

- Linearizing the capital Euler equation (A.5) gives

$$
\hat{\lambda}_{t}+\hat{q}_{t}=E_{t} \hat{\lambda}_{t+1}+\beta r^{k} E_{t} \hat{r}_{t+1}^{k}+\beta(1-\delta) E_{t} \hat{q}_{t+1}+\beta \phi \delta^{2} E_{t}\left(\hat{I}_{t+1}-\hat{K}_{t+1}\right)
$$

- Linearizing the law of motion for capital (A.6) gives

$$
\hat{K}_{t+1}=(1-\delta) \hat{K}_{t}+\delta\left(\hat{I}_{t}+\hat{a}_{t}\right)
$$

- Linearizing the no-shirking condition (A.7) gives

$$
\left(C^{e} / C-b\right)\left(\hat{h}_{t}+\hat{w}_{t}\right)=\left(C^{e} / C\right) \hat{C}_{t}^{e}-b \hat{C}_{t-1}
$$

- Linearizing the consumption risk-sharing condition (A.8) gives

$$
\left(C^{u} / C\right) \hat{C}_{t}^{u}=\mu\left(C^{e} / C\right) \hat{C}_{t}^{e}+(1-\mu) b \hat{C}_{t-1}
$$

- Linearizing the equation for average consumption (A.9) gives

$$
\hat{C}_{t}=\left(C^{e} / C\right) N \hat{C}_{t}^{e}+\left(C^{u} / C\right)(1-N) \hat{C}_{t}^{u}+(1-\mu)\left(\left(C^{e} / C\right)-b\right) N \hat{N}_{t}
$$


- Linearizing the aggregate resource constraint (A.10) gives

$$
\hat{Y}_{t}=(C / Y) \hat{C}_{t}+(I / Y) \hat{I}_{t}
$$

- Linearizing the marginal product of capital (A.11) gives

$$
\hat{r}_{t}^{k}=\hat{m} c_{t}+\hat{z}_{t}+(\alpha-1)\left(\hat{K}_{t}-\hat{N}_{t}\right)
$$

- Linearizing the marginal product of labor (A.12) gives

$$
\hat{h}_{t}+\hat{w}_{t}=\hat{m} c_{t}+\hat{z}_{t}+\alpha\left(\hat{K}_{t}-\hat{N}_{t}\right)
$$

- Linearizing the aggregate production function (A.13) gives

$$
\hat{Y}_{t}+\hat{\Delta}_{t}=\hat{z}_{t}+\alpha \hat{K}_{t}+(1-\alpha) \hat{N}_{t}
$$

- Linearizing the aggregate profit equation (A.14) gives

$$
\hat{D}_{t}=\hat{Y}_{t}-\frac{1}{\eta}\left(\hat{m} c_{t}+\hat{\Delta}_{t}\right)
$$

- Linearizing the equation for family consumption (A.15) gives

$$
((C / Y)-(1-\alpha) m c) \hat{C}_{t}^{f}=(C / Y) \hat{C}_{t}-(1-\alpha) m c\left(\hat{h}_{t}+\hat{w}_{t}+\hat{N}_{t}\right)
$$

- Linearizing the monetary policy rule (A.16) gives

$$
\hat{R}_{t}=\theta_{R} \hat{R}_{t-1}+\left(1-\theta_{R}\right)\left[\theta_{\pi} \hat{\pi}_{t}+\theta_{Y 0} \hat{Y}_{t}+\theta_{Y 1} \hat{Y}_{t-1}+\theta_{w 0} \hat{w}_{t}+\theta_{w 1} \hat{w}_{t-1}\right]+\varepsilon_{R, t}
$$

- Assuming $\hat{\Delta}_{-1}=0$, linearizing the equation for price dispersion (A.18) gives

$$
\hat{\Delta}_{t}=0
$$

- Combining the linear approximations to (A.17) and (A.19) gives the Phillips curve

$$
\left(\hat{\pi}_{t}-\gamma \hat{\pi}_{t-1}\right)=\beta E_{t}\left(\hat{\pi}_{t+1}-\gamma \hat{\pi}_{t}\right)+\frac{(1-\chi)(1-\beta \chi)}{\chi}\left(\hat{m} c_{t}+\frac{\eta}{1+\eta} \hat{\eta}_{t}\right)
$$

- Linearizing the neutral technology shock gives

$$
\hat{z}_{t}=\rho_{z} \hat{z}_{t-1}+\varepsilon_{z, t}
$$

- Linearizing the time rate of preference shock gives

$$
\hat{g}_{t}=\rho_{g} \hat{g}_{t-1}+\varepsilon_{g, t}
$$


- Linearizing the investment-specific technology shock gives

$$
\hat{a}_{t}=\rho_{a} \hat{a}_{t-1}+\varepsilon_{a, t}
$$

- Linearizing the markup shock gives

$$
\hat{\eta}_{t}=\log \left(\varepsilon_{\eta, t}\right)
$$

- Linearizing the intensive margin shock gives

$$
\hat{h}_{t}=\log \left(\varepsilon_{h, t}\right)
$$

\section{Appendix D. The State-Space Econometric Model}

The data available to the econometrician includes average consumption $C_{t}$, investment $I_{t}$, the real wage $w_{t}$, inflation $\pi_{t}$, and the one-period nominal interest rate $R_{t}$. These data can be used to collect a history of observations $\left\{\mathbf{d}_{t}\right\}_{t=1}^{T}$, where the vector $\mathbf{d}_{t}=\left[\hat{C}_{t} \hat{I}_{t} \hat{w}_{t} \hat{\pi}_{t} \hat{R}_{t}\right]^{\prime}$. The reduced-form solution of the shirking model given by (18) and (19) takes the form of a state-space econometric model

$$
\begin{gathered}
\mathbf{s}_{t}=\Pi \mathbf{s}_{t-1}+\Omega \varepsilon_{t} \\
\mathbf{d}_{t}=\Gamma \mathbf{s}_{t}
\end{gathered}
$$

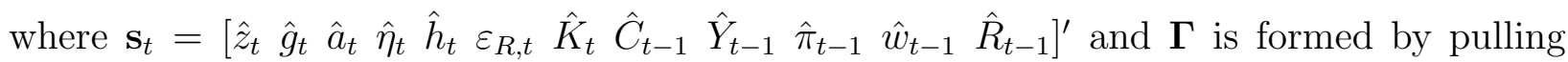
out the appropriate rows of $\mathbf{U}$ in (19). The vector of serially uncorrelated innovations $\varepsilon_{t}=\left[\varepsilon_{z, t} \varepsilon_{g, t} \varepsilon_{a, t} \log \left(\varepsilon_{\eta, t}\right) \log \left(\varepsilon_{h, t}\right) \varepsilon_{R, t}\right]^{\prime}$ is assumed to be mean-zero, normally distributed with diagonal covariance matrix $V=E \varepsilon \varepsilon_{t}^{\prime}=\left[\begin{array}{lllll}\sigma_{z}^{2} & \sigma_{g}^{2} & \sigma_{a}^{2} & \sigma_{\eta}^{2} & \sigma_{h}^{2} \\ \sigma_{R}^{2}\end{array}\right] \times I_{6}$.

The state-space representation of the model given by (D.1) and (D.2) can be used to calculate the sample likelihood function with the Kalman filtering algorithms described in Hamilton (1994, Ch. 13). Denote $\Theta$ the vector of structural coefficients, the parameters governing the distributions of the shocks, and the policy rule coefficients. Log likelihood for 
a sample of size $T$ is

$$
\begin{array}{r}
\log \mathcal{L}\left(\Theta \mid \mathbf{d}_{1}, \ldots, \mathbf{d}_{T}\right)=\frac{-5 T}{2} \log (2 \pi)-\frac{1}{2} \sum_{t=1}^{T} \log \left|\boldsymbol{\Gamma} \hat{\Sigma}_{t \mid t-1} \boldsymbol{\Gamma}^{\prime}\right| \\
-\frac{1}{2} \sum_{t=1}^{T}\left(\mathbf{d}_{t}-\boldsymbol{\Gamma} \hat{\mathbf{s}}_{t \mid t-1}\right)^{\prime}\left(\boldsymbol{\Gamma} \hat{\Sigma}_{t \mid t-1} \boldsymbol{\Gamma}^{\prime}\right)^{-1}\left(\mathbf{d}_{t}-\boldsymbol{\Gamma} \hat{\mathbf{s}}_{t \mid t-1}\right)
\end{array}
$$

where $\hat{\mathbf{s}}_{t \mid t-1}$ and $\hat{\Sigma}_{t \mid t-1}$ are the one-step-ahead optimal forecasts of the mean and variance of $\mathbf{s}_{t}$. They are calculated recursively according to the following updating scheme:

$$
\begin{aligned}
\mathbf{K}_{t} & =\boldsymbol{\Pi} \hat{\mathbf{s}}_{t \mid t-1} \boldsymbol{\Gamma}^{\prime}\left(\boldsymbol{\Gamma} \hat{\Sigma}_{t \mid t-1} \boldsymbol{\Gamma}^{\prime}\right)^{-1}, \\
\hat{\mathbf{s}}_{t+1 \mid t} & =\boldsymbol{\Pi} \hat{\mathbf{s}}_{t \mid t-1}+\mathbf{K}_{t}\left(\mathbf{d}_{t}-\boldsymbol{\Gamma} \hat{\mathbf{s}}_{t \mid t-1}\right), \\
\hat{\Sigma}_{t+1 \mid t} & =\left(\boldsymbol{\Pi}-\mathbf{K}_{t} \boldsymbol{\Gamma}\right) \hat{\Sigma}_{t \mid t-1}\left(\boldsymbol{\Pi}-\mathbf{K}_{t} \boldsymbol{\Gamma}\right)^{\prime}+\Omega V \boldsymbol{\Omega}^{\prime},
\end{aligned}
$$

where $\mathbf{K}_{t}$ is the Kalman gain matrix. Parameter estimates are obtained by numerically maximizing the likelihood function over the elements of $\Theta$. The first three observations from the sample are used to initialize the Kalman filter and are not included in the value of $\log \mathcal{L}$. 


\section{References}

Alexopoulos, Michelle. "Unemployment and the Business Cycle." Journal of Monetary Economics, March 2004, 51(2), pp. 277-98.

- "Shirking in a Monetary Business Cycle Model." Canadian Journal of Economics, August 2006, 39(3), pp. 689-718.

. "A Monetary Business Cycle Model with Unemployment." Journal of Economic Dynamics and Control, December 2007, 31(12), pp. 3904-40.

Amato, Jeffrey D. and Laubach, Thomas. "Estimation and Control of an OptimizationBased Model with Sticky Prices and Wages." Journal of Economic Dynamics and Control, May 2003, 27(7), pp. 1181-215.

Andolfatto, David. "Business Cycles and Labor-Market Search." American Economic Review, March 1996, 86(1), pp. 112-32.

Basu, Susanto and Fernald, John G. "Returns to Scale in U.S. Production: Estimates and Implications." Journal of Political Economy, April 1997, 105(2), pp. 249-83.

Boldrin, Michele; Christiano, Lawrence J. and Fisher, Jonas D.M. "Habit Persistence, Asset Returns, and the Business Cycle." American Economic Review, March 2001, 91(1), pp. 149-66.

Calvo, Guillermo A. "Staggered Prices in a Utility-Maximizing Framework." Journal of Monetary Economics, September 1983, 12(3), pp. 383-98.

Christiano, Lawrence J. and Eichenbaum, Martin. "Current Real-Business-Cycle Theories and Aggregate Labor-Market Fluctuations." American Economic Review, June 1992, 82(3), pp. 430-50.

Christiano, Lawrence J.; Eichenbaum, Martin and Evans, Charles L. "Nominal Rigidities and the Dynamic Effects of a Shock to Monetary Policy." Journal of Political Economy, January 2005, 113(1), pp. 1-45.

Clarida, Richard; Galí, Jordi and Gertler, Mark. "The Science of Monetary Policy: A New Keynesian Perspective." Journal of Economic Literature, December 1999, 37(4), pp. 1661-707.

. "Monetary Policy Rules and Macroeconomic Stability: Evidence and Some Theory." The Quarterly Journal of Economics, February 2000, 115(1), pp. 147-80.

Danthine, Jean-Pierre and Donaldson, John B. "Efficiency Wages and the Business Cycle Puzzle." European Economic Review, November 1990, 34(7), pp. 1275-301. 
Danthine, Jean-Pierre and Kurmann, André. "Fair Wages in a New Keynesian Model of the Business Cycle." Review of Economic Dynamics, January 2004, 7(1), pp. 107-42.

Dixit, Avinash K. and Stiglitz, Joseph E. "Monopolistic Competition and Optimum Product Diversity." American Economic Review, June 1977, 67(3), pp. 297-308.

Dynarksi, Mark and Sheffrin, Steven M. "Consumption and Unemployment." The Quarterly Journal of Economics, May 1987, 102(2), pp. 411-28.

Fisher, Jonas D.M. "The Dynamic Effects of Neutral and Investment-Specific Technology Shocks." Journal of Political Economy, June 2006, 114(3), pp. 413-51.

Fuhrer, Jeffrey C. "Habit Formation in Consumption and its Implications for MonetaryPolicy Models." American Economic Review, June 2000, 90(3), pp. 367-90.

Fuhrer, Jeffrey C. and Moore, George R. "Inflation Persistence." The Quarterly Journal of Economics, February 1995, 110(1), pp. 127-59.

Galí, Jordi and Gertler, Mark. "Inflation Dynamics: A Structural Econometric Analysis." Journal of Monetary Economics, October 1999, 44(2), pp. 195-222.

Giannoni, Marc P. and Woodford, Michael. "Optimal Inflation-Targeting Rules," in Ben S. Bernanke and Michael Woodford, eds., The Inflation Targeting Debate. Chicago, IL: University of Chicago Press, 2004, pp. 93-162.

Givens, Gregory E. "Unemployment, Imperfect Risk Sharing, and the Monetary Business Cycle." The B.E. Journal of Macroeconomics, March 2008, 8(1) (Contributions), Article 13.

Gomme, Paul. "Shirking, Unemployment, and Aggregate Fluctuations." International Economic Review, February 1999, 40(1), pp.3-21.

Greenwood, Jeremy; Hercowitz, Zvi and Huffman, Gregory W. "Investment, Capacity Utilization, and the Real Business Cycle." American Economic Review, June 1988, 78(3), pp. 402-17.

Gruber, Jonathon. "The Consumption Smoothing Benefits of Unemployment Insurance." American Economic Review, March 1997, 87(1), pp. 192-205.

Hall, George J. "Overtime, Effort, and the Propagation of Business Cycle Shocks." 'Journal of Monetary Economics, August 1996, 38(1), pp. 139-60.

Hamilton, James D. Time Series Analysis. Princeton, NJ: Princeton University Press, 1994. 
Ireland, Peter N. "Sticky-Price Models of the Business Cycle: Specification and Stability." Journal of Monetary Economics, February 2001, 47(1), pp. 3-18.

. "Endogenous Money or Sticky Prices?" Journal of Monetary Economics, November 2003, 50(8), pp. 1623-48.

. "A Method for Taking Models to the Data." Journal of Economic Dynamics and Control, March 2004a, pp. 1205-26.

. "Technology Shocks in the New Keynesian Model." Review of Economics and Statistics, November 2004b, 86(4), pp. 923-36.

. "Changes in the Federal Reserve's Inflation Target: Causes and Consequences." Journal of Money, Credit, and Banking, December 2007, 39(8), pp. 1851-82.

Justiniano, Alejandro; Primiceri, Giorgio E. and Tambalotti, Andrea. "Investment Shocks and Business Cycles." Federal Reserve Bank of New York Staff Reports, No. 322, March 2008.

Kim, Jinill. "Constructing and Estimating a Realistic Optimizing Model of Monetary Policy." Journal of Monetary Economics, April 2000, 45(2), pp. 329-59.

King, Robert G. and Rebelo, Sergio T. "Resuscitating Real Business Cycles," in John B. Taylor and Michael Woodford, eds., Handbook of Macroeconomics, 1999, Volume 1, Part 2, pp. 927-1007.

King, Robert G. and Watson, Mark W. "Money, Prices, Interest Rates, and the Business Cycle." Review of Economics and Statistics, February 1996, 78(1), pp. 35-53.

Klein, Paul. "Using the Generalized Schur Form to Solve a Multivariate Linear Rational Expectations Model." Journal of Economic Dynamics and Control, September 2000, 24(10), pp. 1405-23.

Levin, Andrew T.; Onatski, Alexie; Williams, John C. and Williams, Noah. "Monetary Policy Under Uncertainty in Micro-Founded Macroeconometric Models," in Mark Gertler and Keneth Rogoff, eds., NBER Macroeconomics Annual 2005. Cambridge, MA: MIT Press, 2005, pp. 229-87.

McCallum, Bennett T. and Nelson, Edward. "An Optimizing IS-LM Specification for Monetary Policy and Business Cycle Analysis." Journal of Money, Credit, and Banking, August 1999, 31(3), pp. 296-316.

McGratten, Ellen R. "The Macroeconomic Effects of Distortionary Taxation." Journal of Monetary Economics, June 1994, 33(3), pp. 573-601. 
Merz, Monika. "Search in the Labor Market and the Real Business Cycle." Journal of Monetary Economics, November 1995, 36(2), pp. 269-300.

Nakamura, Emi and Steinsson, Jón. "Five Facts About Prices: A Reevaluation of Menu Cost Models." forthcoming in The Quarterly Journal of Economics, 2008.

Rabanal, Pau and Rubio-Ramírez, Juan F. "Comparing New Keynesian Models of the Business Cycle: A Bayesian Approach." Journal of Monetary Economics, September 2005, 52(6), pp. 1151-66.

Ruge-Murcia, Francisco J. "Methods to Estimate Dynamic Stochastic General Equilibrium Models." Journal of Economic Dynamics and Control, August 2007, 31(8), pp. 2599-636.

Shapiro, Carl and Stiglitz, Joseph E. "Equilibrium Unemployment as a Worker Discipline Device." American Economic Review, June 1984, 74(3), pp. 433-44.

Smets, Frank and Wouters, Raf. "An Estimated Dynamic Stochastic General Equilibrium Model of the Euro Area." Journal of the European Economic Association, September 2003, 1(5), pp. 1123-75.

- "Comparing Shocks and Frictions in US and Euro Area Business Cycles: A Bayesian DSGE Approach." Journal of Applied Econometrics, March 2005, 20(2), pp. 161-83.

- "Shocks and Frictions in US Business Cycles: A Bayesian DSGE Approach." American Economic Review, June 2007, 97(3), pp. 586-606.

Solow, Robert M. "Another Possible Source of Wage Stickiness." Journal of Macroeconomics, Winter 1979, 1(1), pp. 79-82.

Steinsson, Jón. "Optimal Monetary Policy in an Economy with Inflation Persistence." Journal of Monetary Economics, October 2003, 50(7), pp. 1425-56.

Taylor, John B. "Discretion Versus Policy Rules in Practice." Carnegie-Rochester Conference Series on Public Policy, December 1993, 39, pp. 195-214.

White, Halbert. "Maximum Likelihood Estimation of Misspecified Models." Econometrica, January 1982, 50(1), pp. 1-25. 
Table 1: Maximum Likelihood Estimates

\begin{tabular}{lrrrr}
\hline \hline \multirow{2}{*}{ Parameter } & \multicolumn{2}{c}{ A. Full Sample } & \multicolumn{2}{c}{ B. Post-1979 Subsample } \\
& Partial Insurance & Full Insurance & Partial Insurance & Full Insurance \\
\hline$\phi$ & $35.5851(7.4022)$ & $15.9882(1.6080)$ & $81.3042(5.0330)$ & $41.5515(7.2052)$ \\
$b$ & $0.2517(0.1031)$ & $0.3582(0.0415)$ & $0.3032(0.2200)$ & $0.4409(0.0588)$ \\
$\gamma$ & $1.0000(0.0000)$ & $0.0000(0.0000)$ & $1.0000(0.0000)$ & $0.0000(0.0000)$ \\
$\mu$ & $0.4773(0.0250)$ & $1^{*}$ & $0.4027(0.0413)$ & $1^{*}$ \\
$\theta_{R}$ & $0.8419(0.0290)$ & $0.7324(0.0268)$ & $0.8479(0.0439)$ & $0.7666(0.0373)$ \\
$\theta_{\pi}$ & $1.8143(0.3294)$ & $1.5157(0.1085)$ & $2.6466(0.5062)$ & $2.1242(0.3167)$ \\
$\theta_{Y 0}$ & $0.6581(0.1355)$ & $0.4407(0.0701)$ & $0.8460(0.3310)$ & $0.5530(0.1673)$ \\
$\theta_{Y 1}$ & $-0.6299(0.1374)$ & $-0.3924(0.0684)$ & $-0.7884(0.3232)$ & $-0.5056(0.1658)$ \\
$\theta_{w 0}$ & $-0.3139(0.2509)$ & $-0.0866(0.0730)$ & $0.1444(0.3706)$ & $0.0538(0.2338)$ \\
$\theta_{w 1}$ & $0.1988(0.2492)$ & $-0.0178(0.0666)$ & $-0.2566(0.3819)$ & $-0.1562(0.2368)$ \\
$\rho_{z}$ & $0.9269(0.0259)$ & $0.9086(0.0219)$ & $0.9865(0.0579)$ & $0.9589(0.0308)$ \\
$\rho_{g}$ & $0.8744(0.0235)$ & $0.9353(0.0320)$ & $0.8907(0.0230)$ & $0.9398(0.0295)$ \\
$\rho_{a}$ & $0.8856(0.0420)$ & $0.9020(0.0276)$ & $0.9065(0.0319)$ & $0.8741(0.0381)$ \\
$\sigma_{z}$ & $0.0096(0.0012)$ & $0.0165(0.0019)$ & $0.0085(0.0015)$ & $0.0140(0.0023)$ \\
$\sigma_{g}$ & $0.0205(0.0034)$ & $0.0125(0.0030)$ & $0.0317(0.0064)$ & $0.0208(0.0057)$ \\
$\sigma_{a}$ & $0.0388(0.0103)$ & $0.0218(0.0024)$ & $0.0849(0.0113)$ & $0.0468(0.0096)$ \\
$\sigma_{\eta}$ & $0.0056(0.0004)$ & $0.0012(0.0004)$ & $0.0050(0.0006)$ & $0.0011(0.0003)$ \\
$\sigma_{h}$ & $0.0075(0.0020)$ & $0.0300(0.0014)$ & $0.0080(0.0037)$ & $0.0347(0.0020)$ \\
$\sigma_{R}$ & $0.0019(0.0002)$ & $0.0021(0.0002)$ & $0.0018(0.0002)$ & $0.0019(0.0002)$ \\
\hline $\log \mathcal{L}$ & 3143.05 & 3079.74 & 1835.98 & 1801.04 \\
\hline \hline
\end{tabular}

Notes: The numbers in parenthesis are standard errors. The superscript * denotes a parameter value that is imposed prior to estimation. The term $\log \mathcal{L}$ denotes the maximized value of the log-likelihood function. 
Table 2: Second Moment Properties

\begin{tabular}{|c|c|c|c|c|c|c|}
\hline & \multicolumn{6}{|c|}{$X$} \\
\hline & $C$ & $I$ & $w$ & $N$ & $\pi$ & $R$ \\
\hline \multicolumn{7}{|c|}{ A. U.S. Data: Full Sample } \\
\hline$\sigma_{X} / \sigma_{Y}$ & 0.7852 & 2.6198 & 0.8000 & 0.3827 & 0.1481 & 0.1679 \\
\hline$\rho(X, Y)$ & 0.9477 & 0.8793 & 0.5380 & 0.7223 & 0.1520 & -0.0653 \\
\hline$\rho(X, w)$ & 0.5902 & 0.3521 & 1.0000 & 0.1096 & 0.4692 & -0.0511 \\
\hline \multicolumn{7}{|c|}{ B. Unrestricted Model: Partial Insurance } \\
\hline$\sigma_{X} / \sigma_{Y}$ & 0.8109 & 2.0234 & 0.7344 & 0.8375 & 0.1266 & 0.0984 \\
\hline$\rho(X, Y)$ & 0.9128 & 0.8747 & 0.6064 & 0.7203 & 0.0525 & -0.0774 \\
\hline$\rho(X, w)$ & 0.8478 & 0.1813 & 1.0000 & -0.0481 & 0.4690 & 0.2125 \\
\hline \multicolumn{7}{|c|}{ C. Restricted Model: Full Insurance } \\
\hline$\sigma_{X} / \sigma_{Y}$ & 0.8207 & 2.1232 & 1.0127 & 0.5616 & 0.0924 & 0.0924 \\
\hline$\rho(X, Y)$ & 0.8871 & 0.8491 & 0.7544 & 0.3692 & 0.4477 & 0.3030 \\
\hline$\rho(X, w)$ & 0.8323 & 0.4539 & 1.0000 & 0.0946 & 0.4857 & 0.1892 \\
\hline \multicolumn{7}{|c|}{ D. Unrestricted Model: Full Insurance } \\
\hline$\sigma_{X} / \sigma_{Y}$ & 0.8902 & 1.9980 & 0.9261 & 0.7565 & 0.1397 & 0.1158 \\
\hline$\rho(X, Y)$ & 0.8926 & 0.8035 & 0.8791 & 0.5730 & 0.4281 & 0.2857 \\
\hline$\rho(X, w)$ & 0.9806 & 0.4476 & 1.0000 & 0.3746 & 0.4455 & 0.1854 \\
\hline
\end{tabular}

Notes: The standard deviation of a variable $X$ relative to the standard deviation of output $Y$ is denoted $\sigma_{X} / \sigma_{Y}$. Output is defined in both the data and the model as consumption plus investment. The contemporaneous correlations between $X$ and $Y$ and between $X$ and $w$ are denoted $\rho(X, Y)$ and $\rho(X, w)$, respectively. All three statistics are calculated for the US data (A), the unrestricted model with partial insurance (B), the restricted model with full insurance $(\mathrm{C})$, and the unrestricted model with full insurance imposed after estimation (D). 
Table 3: Variance Decompositions under Partial Insurance

\begin{tabular}{|c|c|c|c|c|c|c|}
\hline Variable & $\begin{array}{l}\text { Neutral } \\
\text { Shock } z_{t}\end{array}$ & $\begin{array}{l}\text { Preference } \\
\text { Shock } g_{t}\end{array}$ & $\begin{array}{l}\text { Investment } \\
\text { Shock } a_{t}\end{array}$ & $\begin{array}{l}\text { Cost-Push } \\
\text { Shock } \eta_{t}\end{array}$ & $\begin{array}{l}\text { Hours } \\
\text { Shock } h_{t}\end{array}$ & $\begin{array}{l}\text { Policy } \\
\text { Shock } \varepsilon_{R, t}\end{array}$ \\
\hline \multicolumn{7}{|c|}{ A. 1-Year Horizon } \\
\hline$Y$ & 31.090 & 2.741 & 35.453 & 24.946 & 0.025 & 5.746 \\
\hline$C$ & 47.681 & 21.838 & 1.861 & 23.705 & 0.019 & 4.897 \\
\hline$I$ & 4.877 & 4.041 & 79.032 & 9.510 & 0.012 & 2.528 \\
\hline$w$ & 51.947 & 10.371 & 28.464 & 0.204 & 8.965 & 0.049 \\
\hline$N$ & 1.025 & 4.583 & 46.104 & 39.217 & 0.039 & 9.033 \\
\hline$\pi$ & 0.051 & 20.145 & 6.059 & 71.436 & 0.007 & 2.302 \\
\hline$R$ & 0.883 & 14.938 & 17.586 & 41.117 & 0.798 & 24.678 \\
\hline \multicolumn{7}{|c|}{ B. 3-Year Horizon } \\
\hline$Y$ & 27.688 & 5.686 & 47.955 & 16.384 & 0.009 & 2.277 \\
\hline$C$ & 49.890 & 11.325 & 17.313 & 19.117 & 0.009 & 2.346 \\
\hline$I$ & 5.768 & 9.254 & 76.011 & 7.695 & 0.006 & 1.265 \\
\hline$w$ & 63.802 & 8.402 & 21.433 & 0.258 & 6.051 & 0.054 \\
\hline$N$ & 0.853 & 9.165 & 54.510 & 30.865 & 0.019 & 4.588 \\
\hline$\pi$ & 1.101 & 30.624 & 7.448 & 57.433 & 0.009 & 3.385 \\
\hline$R$ & 0.528 & 41.426 & 8.239 & 37.813 & 0.356 & 11.637 \\
\hline \multicolumn{7}{|c|}{ C. 10-Year Horizon } \\
\hline$Y$ & 24.000 & 6.355 & 57.551 & 10.630 & 0.006 & 1.459 \\
\hline$C$ & 37.439 & 8.529 & 41.902 & 10.828 & 0.005 & 1.298 \\
\hline$I$ & 6.363 & 9.851 & 76.334 & 6.397 & 0.005 & 1.050 \\
\hline$w$ & 48.618 & 6.038 & 41.019 & 0.755 & 3.502 & 0.068 \\
\hline$N$ & 0.847 & 10.821 & 56.039 & 28.079 & 0.018 & 4.196 \\
\hline$\pi$ & 2.711 & 27.780 & 14.268 & 52.197 & 0.008 & 3.036 \\
\hline$R$ & 0.607 & 44.073 & 11.822 & 33.038 & 0.309 & 10.152 \\
\hline
\end{tabular}

Notes: The numbers correspond to the percentage of the variance of each variable attributed to each shock. 
Table 4: Variance Decompositions under Full Insurance

\begin{tabular}{crrrrrr}
\hline \hline Variable & $\begin{array}{c}\text { Neutral } \\
\text { Shock } z_{t}\end{array}$ & $\begin{array}{l}\text { Preference } \\
\text { Shock } g_{t}\end{array}$ & $\begin{array}{l}\text { Investment } \\
\text { Shock } a_{t}\end{array}$ & $\begin{array}{l}\text { Cost-Push } \\
\text { Shock } \eta_{t}\end{array}$ & $\begin{array}{l}\text { Hours } \\
\text { Shock } h_{t}\end{array}$ & \multicolumn{1}{l}{$\begin{array}{l}\text { Policy } \\
\text { Shock } \varepsilon_{R, t}\end{array}$} \\
\hline A. 1-Year Horizon & & & & & & \\
$Y$ & 67.122 & 0.265 & 21.854 & 0.490 & 1.464 & 8.806 \\
$C$ & 76.270 & 12.018 & 3.296 & 0.382 & 1.158 & 6.876 \\
$I$ & 26.360 & 4.439 & 62.742 & 0.295 & 0.868 & 5.297 \\
$w$ & 25.736 & 4.123 & 1.141 & 0.135 & 66.437 & 2.428 \\
$N$ & 23.671 & 0.733 & 48.239 & 1.245 & 3.719 & 22.393 \\
$\pi$ & 11.459 & 53.312 & 4.724 & 6.787 & 3.515 & 20.204 \\
$R$ & 2.113 & 35.124 & 44.987 & 0.855 & 1.556 & 15.366 \\
& & & & & & \\
B. 3-Year Horizon & & & & & & \\
$Y$ & 75.268 & 0.728 & 19.144 & 0.221 & 0.664 & 3.975 \\
$C$ & 87.507 & 6.241 & 2.428 & 0.174 & 0.529 & 3.122 \\
$I$ & 33.919 & 7.496 & 54.968 & 0.165 & 0.487 & 2.966 \\
$w$ & 45.173 & 3.556 & 1.502 & 0.106 & 47.759 & 1.905 \\
$N$ & 22.272 & 1.599 & 53.071 & 1.049 & 3.144 & 18.865 \\
$\pi$ & 13.308 & 54.905 & 8.668 & 4.972 & 2.691 & 15.456 \\
$R$ & 1.257 & 44.899 & 44.762 & 0.436 & 0.803 & 7.843 \\
& & & & & & \\
C. 10-Year Horizon & & & & & & \\
$Y$ & 70.136 & 1.982 & 24.495 & 0.154 & 0.463 & 2.770 \\
$C$ & 76.853 & 4.280 & 16.507 & 0.107 & 0.326 & 1.927 \\
$I$ & 35.165 & 9.216 & 52.497 & 0.142 & 0.420 & 2.559 \\
$w$ & 48.914 & 3.073 & 10.521 & 0.083 & 35.918 & 1.492 \\
$N$ & 22.782 & 2.240 & 52.774 & 1.010 & 3.028 & 18.165 \\
$\pi$ & 17.784 & 45.553 & 18.640 & 3.864 & 2.099 & 12.059 \\
\hline \hline & 1.700 & 43.275 & 48.001 & 0.337 & 0.622 & 6.065 \\
\hline
\end{tabular}

Notes: The numbers correspond to the percentage of the variance of each variable attributed to each shock. 
Figure 1: Vector Autocorrelation Functions
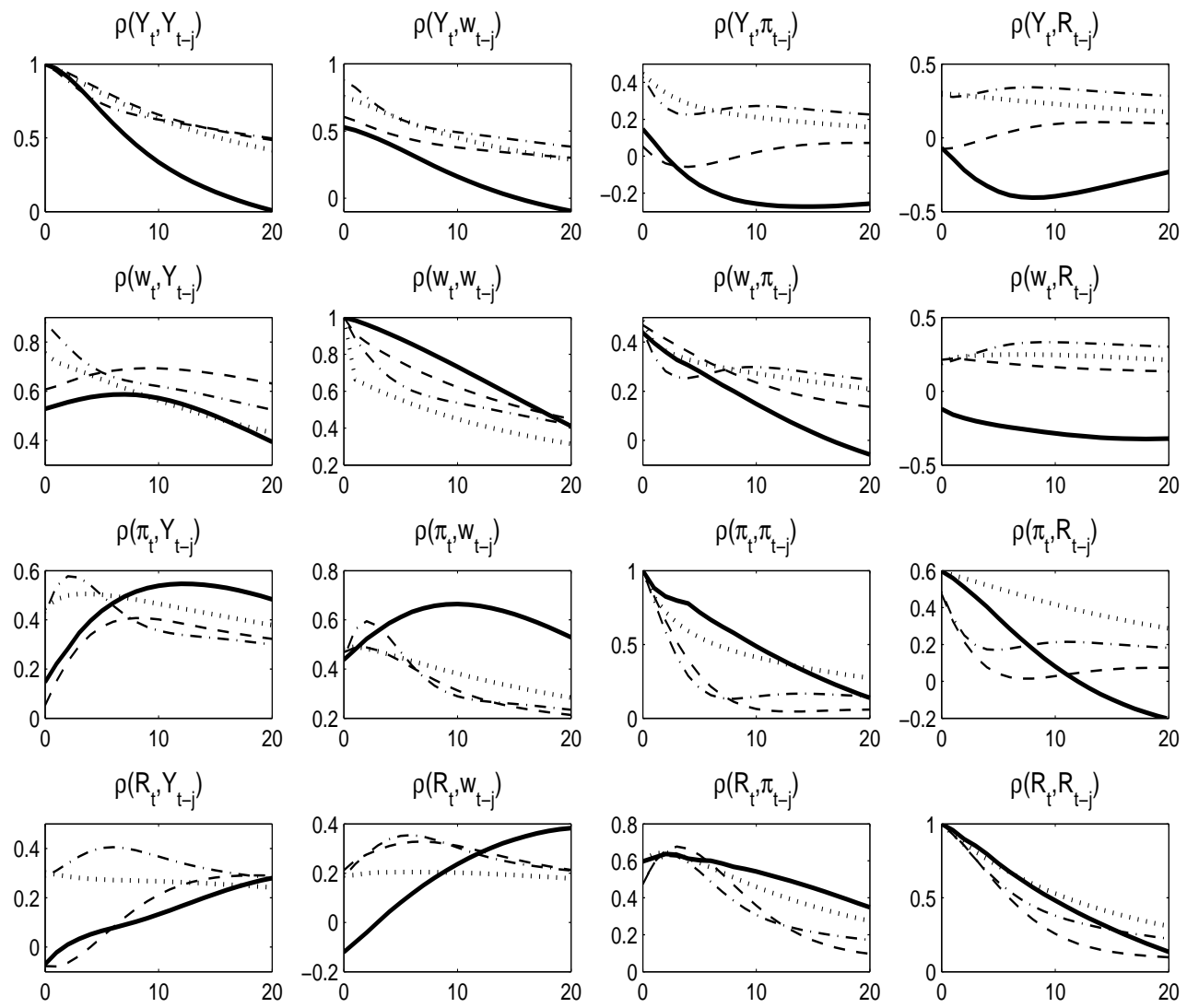

Notes: The figure shows the vector autocorrelation functions for output $Y$, the real wage $w$, inflation $\pi$, and the nominal interest rate $R$ implied by the US data (solid line), the unrestricted model with partial insurance (dashed line), the restricted model with full insurance (dotted line), and the unrestricted model with full insurance imposed after estimation (dot-dashed line). Output is defined in the data as the sum of consumption and investment. 
Figure 2: Impulse Response Functions
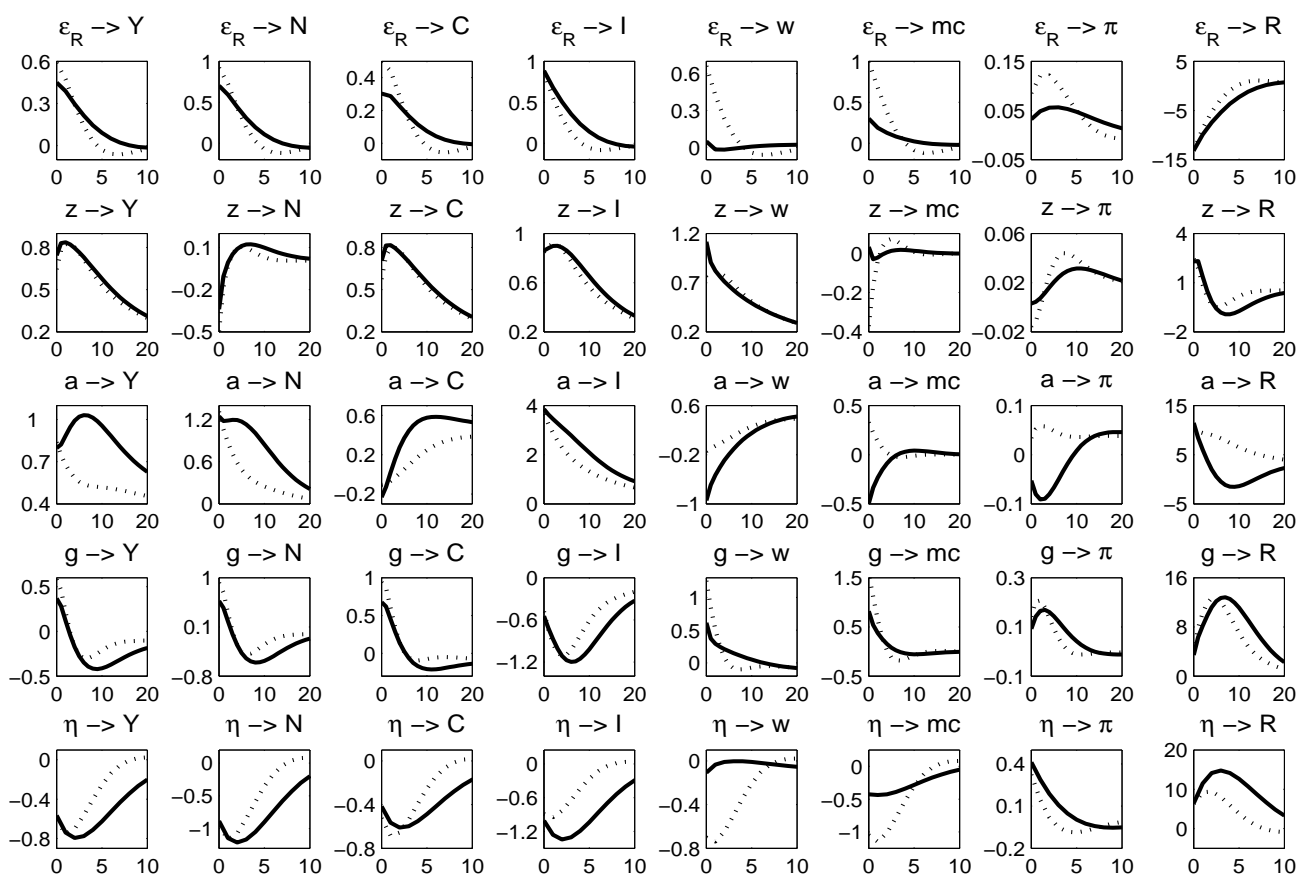

Notes: The figure plots the impulse response functions for output $Y$, employment $N$, average consumption $C$, investment $I$, the real wage $w$, real marginal cost $m c$, inflation $\pi$, and the nominal interest rate $R$. From top to bottom, the rows trace out the response of each variable to an estimated one standard deviation shock to monetary policy $\varepsilon_{R}$, neutral technology $z$, investment-specific technology $a$, time rate of preference $g$, and price markup $\eta$. Variables are measured in percentage point deviations from steady state, and the interest rate is measured in basis points. Response functions are graphed for the unrestricted model with partial insurance (solid line) and the unrestricted model with full insurance imposed after estimation (dotted line). 
Figure 3: One-Step Ahead Forecast Errors

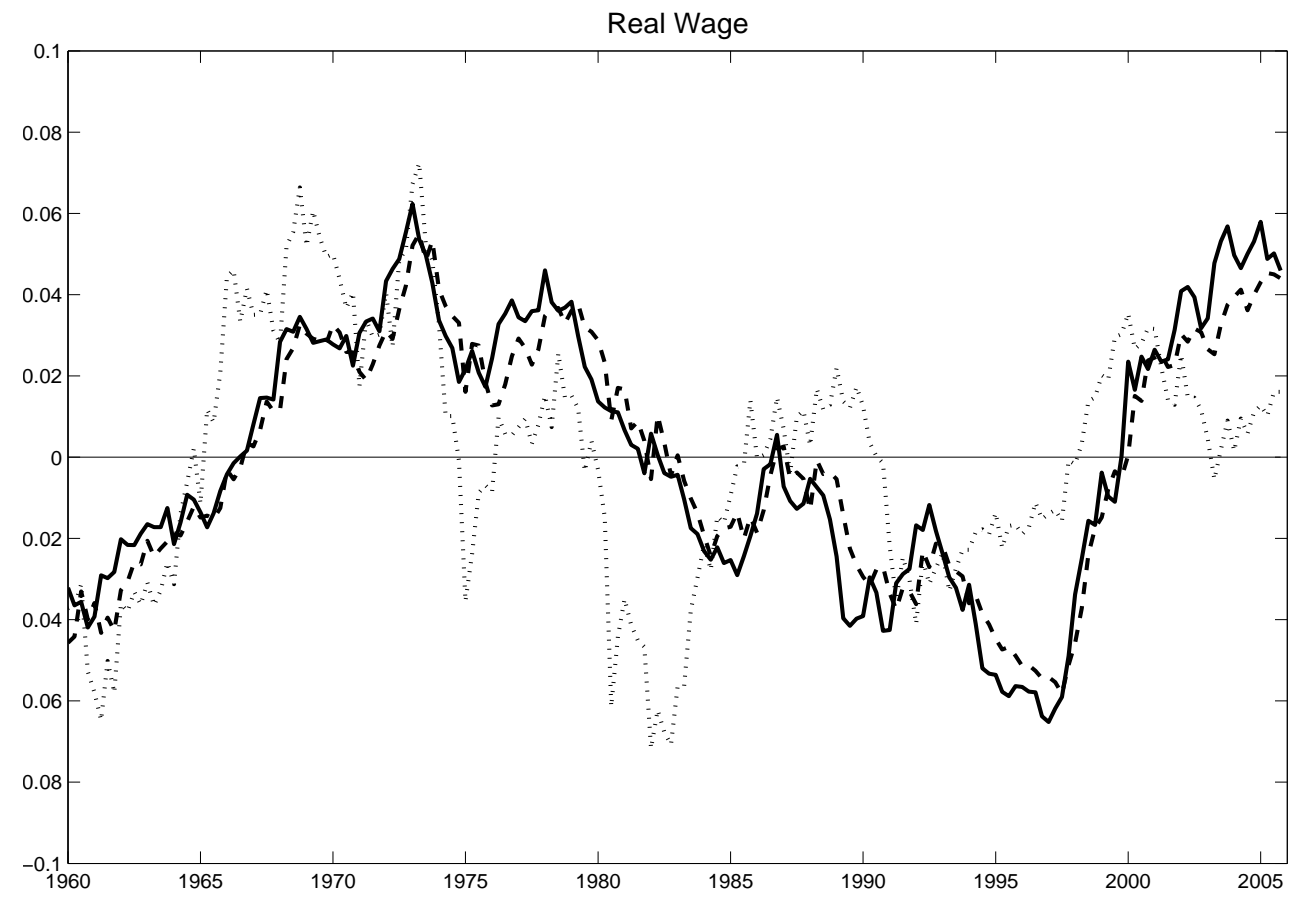

Notes: The figure plots the observed series for the real wage (solid line) as well as the one-step-ahead forecasts predicted by the unrestricted model with partial insurance (dashed line) and the restricted model with full insurance (dotted line). 